\title{
مقاله يثوهشى
}

\section{بررسى ياسخ جوانهزنى بذرهاى زوال يافته گَياه جيا (Salvia hispanica) به سطوح مختلف شورى با استفاده از سه مدل \\ امين حقيقى '، يزدان ايزدى '، ميعاد حاجى محمودى '، سيد امير موسوى "، "}

جكيده مبسوط

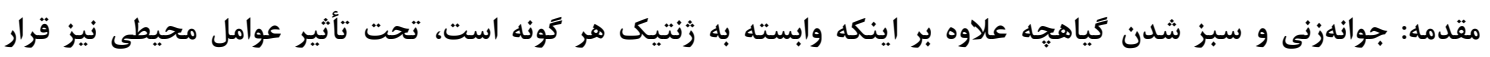

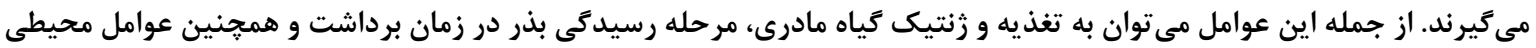

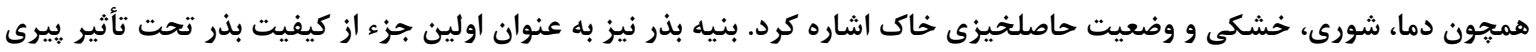

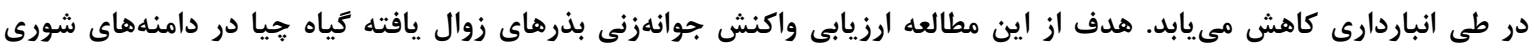
مختلف مىباشد.

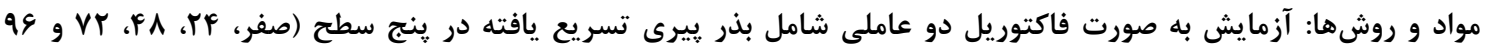

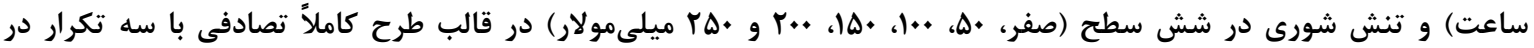

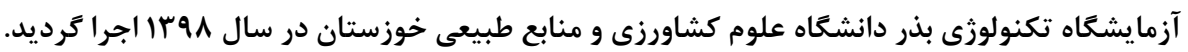

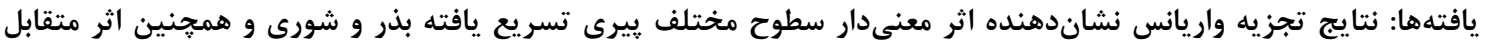

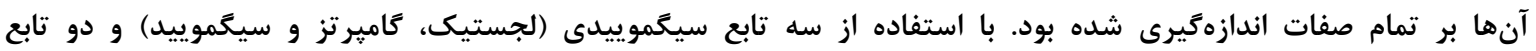

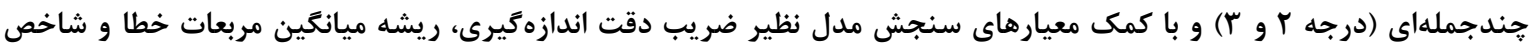

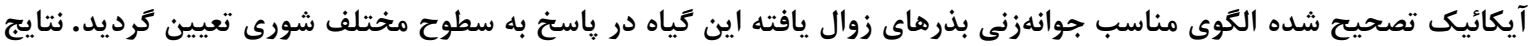

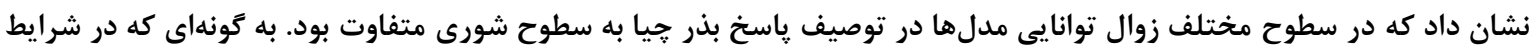

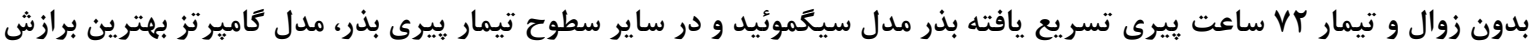

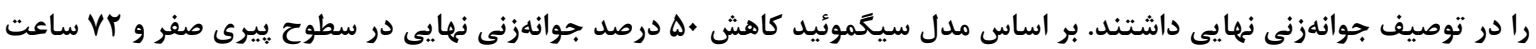

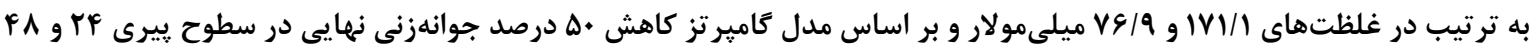

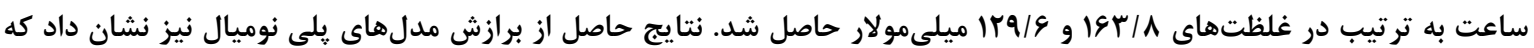

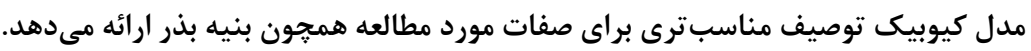

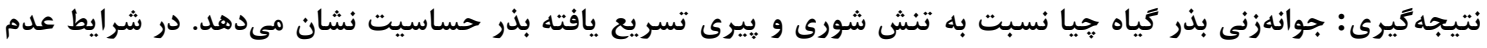

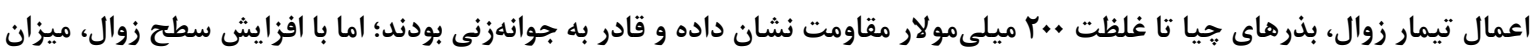

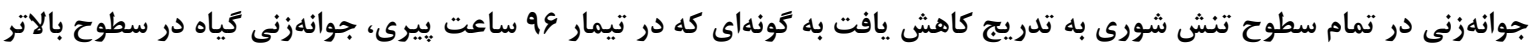

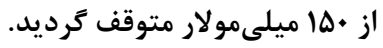

وازههاى كليدى: بنيه بذر، يِيرى تسريعشده، تنش اسمزى، مدلهاى غير خطى جنبdهاى نوآورى:

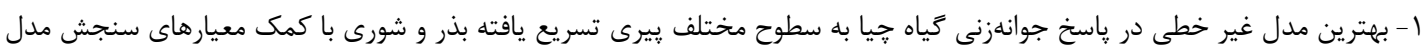
بر آورد ترديد.

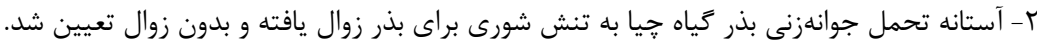

http://dorl.net/dor/20.1001.1.23831251.1399.7.2.11.0

DOI: 10.29252/yujs.7.2.171

CrossMark
' دانشجوى سابق كارشناسى ارشد، تروه مهندسى توليد دياه

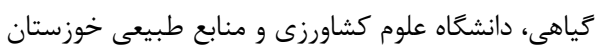

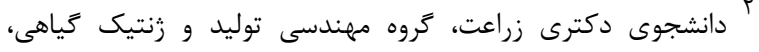

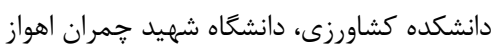

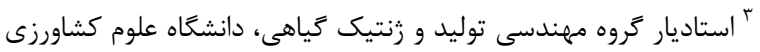
و منابع طبيعى خوزستان 


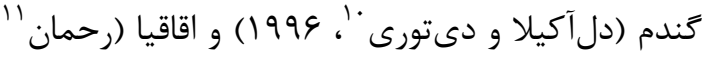
و همكاران، 1999) وجود نداشت. هرجند كزارش شده است كه در بِيرى طبيعى و مصنوعى كاهش معنى دارى در جوانهزنى بذرهاى يونجه در شرايط شور ديده مى بودي (خواجه حسينى و همكاران، ب. • (Y).

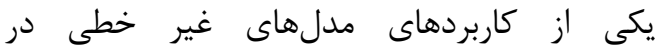

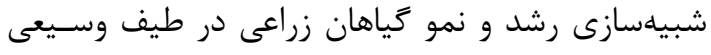

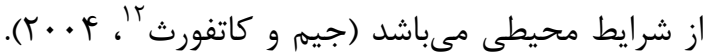
بررسى واكنش جوانهزنى و سبزشدن بـذرها نسبت به به تنشهاى غير زنده از جمله تنش شورى و يِيرى تسريع

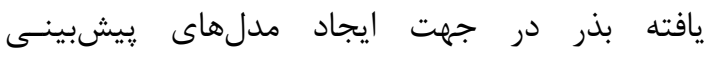
جوانسهزنسى و سبزشـدن، ايجاد شرايط انباردارى مناسب، كزينش كونهها و رنوتيبها براى تحمل به شورى إنهاى

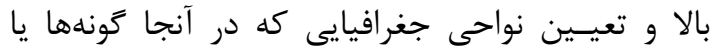
زنوتيبها بتوانند با موفقيت جوانه بزنند و استقرار يابند، مفيـد است. در همين راستا محققان در مطالعات خود

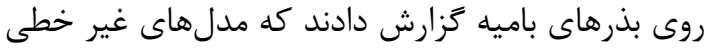

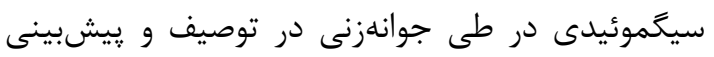
ميزان خسارت بذرها در طى انباردارى مفيد واقع شدند

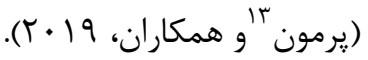
يكى از كياهانى كه در كشور كمتر به آن آن توجه شدها كياه جيا مىباشد (هاديان "و همكاران، نام علمى Salvia hispanica L و نام انگليسى همانى

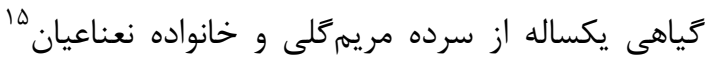
مىباشد. اين كياه بومى آمريكاى مركزى (جنوب

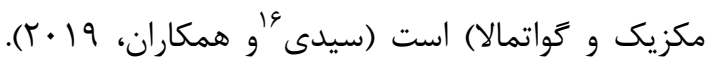
دانههاى آن داراى سطح بالاى يروتئين، آنتى - اكسيدان،

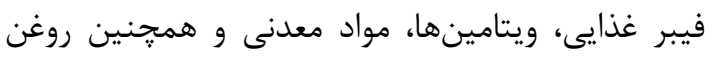
آن حاوى بيشترين مقدار اسيد لينولنيك و اسيد الفا

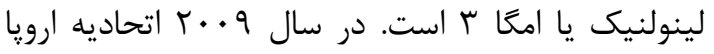

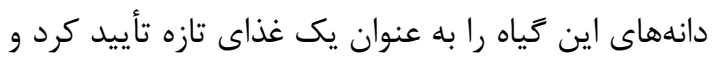

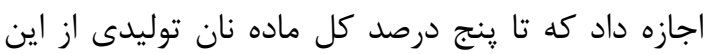

\footnotetext{
${ }^{10}$ Dell Aquila and Di Turi

11 Rehman

12 Jame and Cutforth

${ }^{13}$ Parmoon

${ }^{14}$ Hadian

${ }^{15}$ Lamiaceae

${ }^{16}$ Seyedi
}

مقدمه - مق

از عوامل مههم و تأثير گذار بر جوانهزنى و سبز شدن گياهان، تنش شورى (حاجيوند قاسمآبادى' و همكاران،

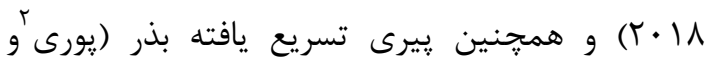

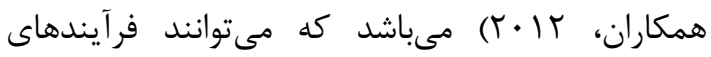
فيزيولوزيكى مهمى را در زياهان تحت تأثير قرار دهد

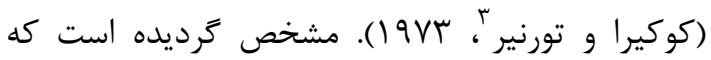
درصد جوانهزنى در شرايط تنش شورى مىتواند به عنوان يك معيار ارزشمند براى طبقهبندى ميزان مقاومت جمعيتهاى گَياهى به اين نوع تنش محيطى ئى

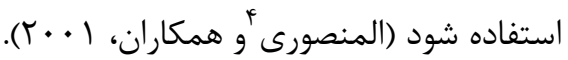

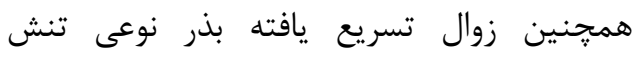
فيزيولوزيكى است كه در شرايط دما و رطوبت نسبى بالا

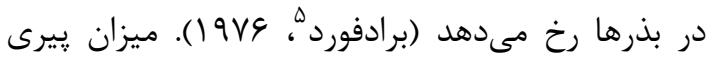
تسريع يافته بذر در بين جمعيتهاى متفاوت بذرى بذى

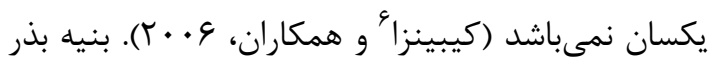
يس از رسيدگى در حداكثر مقدار خود قرار دارد، اما بطور حتم يس از ريزش از روى كياه مادرى و در داخل بانك بذر خاك در همين وضعيت باقى نمىماند و زوال ييدا مى كند. مطالعات مختلفى در مورد اثر ثيرى تسريع

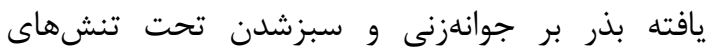

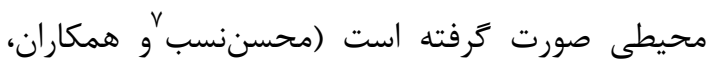

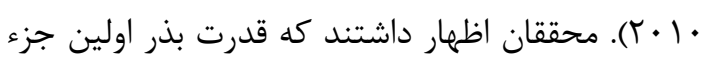

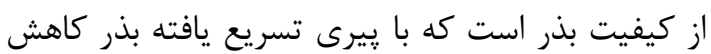
مىيابد و به دنبال آن ظرفيت جوانهزنى و قوهناميه نيز

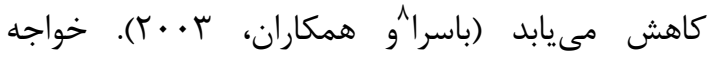

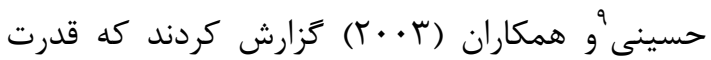
جوانهزنى بذر سويا در شرايط شور پيس از پييرى كاهش

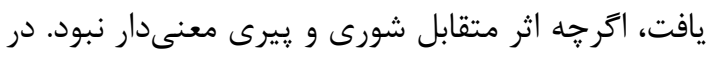

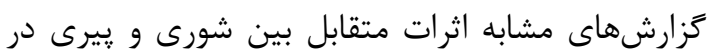

\footnotetext{
${ }^{1}$ Hajivand Ghasemabadi

2 Poori

${ }^{3}$ Kucera and Turner

${ }^{4}$ Almansouri

${ }^{5}$ Bradford

${ }^{6}$ Kibinza

${ }^{7}$ Mohssen nasab

${ }^{8}$ Basra

${ }^{9}$ Khajeh-Hosseini
} 
سيس بلهمنظور انجام آزمون يِيرى تسريع يافته، در

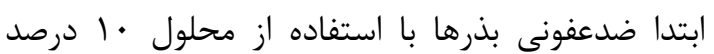

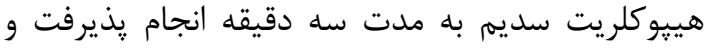
سيس نمونههاى مورد نظر با آب مقطر شستشو داده شدند. درصد رطوبت اوليه بذرها با استفاده از جهار تكرار

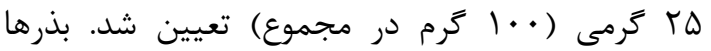
دورن ظروف يترى شيشهاى پيركس قرار گرفته و وزن

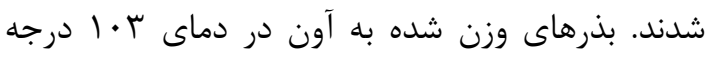

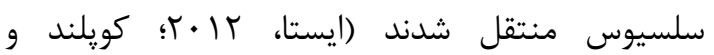

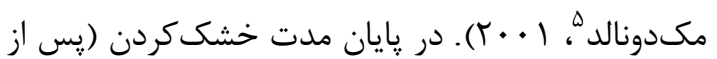

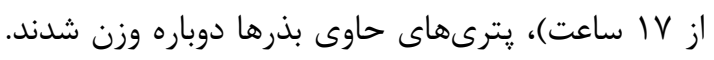

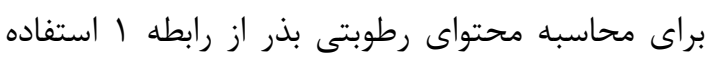

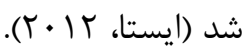
رابطه ا:

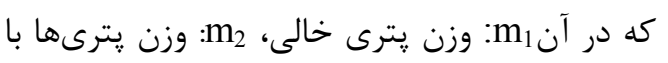

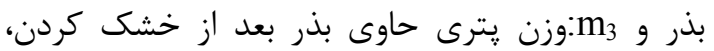
است. درصد رطوبت اوليه بذرها 1 درصد تعيين كرديد.

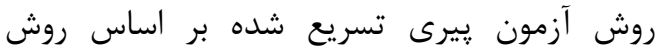

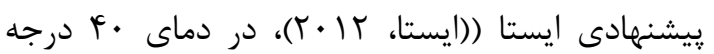

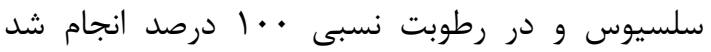

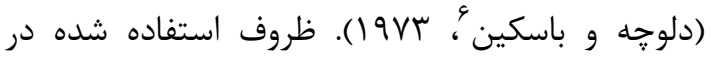

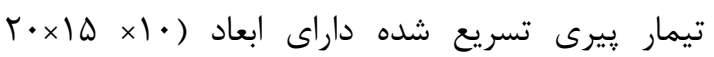

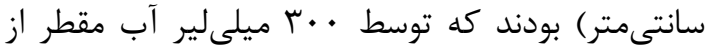
نظر رطوبت نسبى اشباع كامل گرديد. بذرها بهَّونهاى

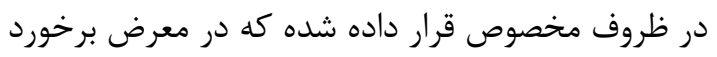

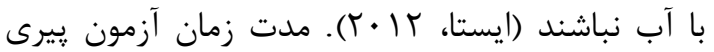

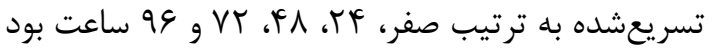

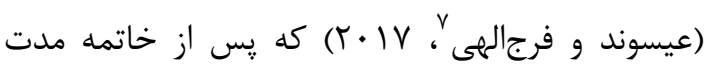
فوق بذرها جهت انجام آزمون جوانهزنى در شرايط اعمال تنش شورى با كلريد سديم، به زرميناتور منتقل كرديد.

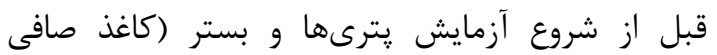

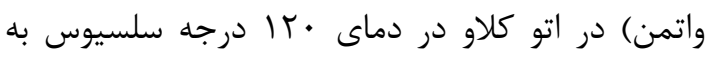

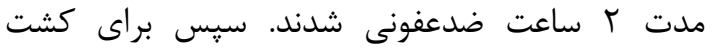
بذرها، به هر يك از ظروف يترى ه ميلىليتر محلول

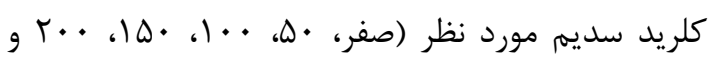

\footnotetext{
${ }^{5}$ Copeland and McDonald

${ }^{6}$ Delouche and Baskin

7 Eisvand and Farajollahi
}

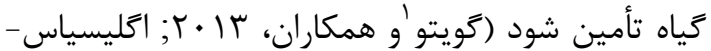

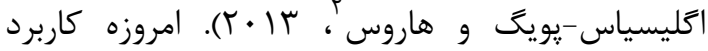

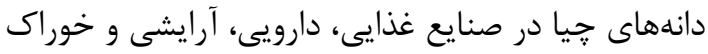

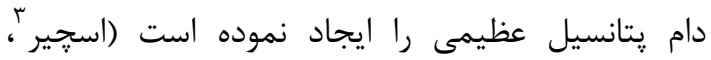

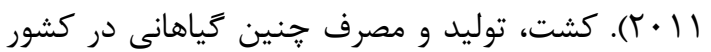
مىتواند ضمن ايجاد اشتغال در بخش كشاورزى و

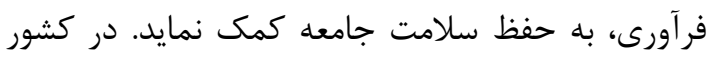
ما تاكنون توليد تجارى اين گياه انجام نشده و اطلاعات كمى در مورد ياسخهاى فنولوزيك و فيزيولوزيك اين

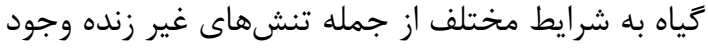

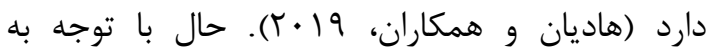

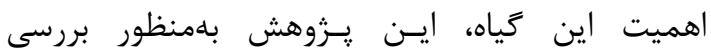

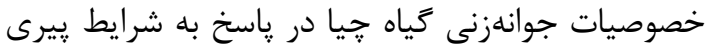
تسريع يافته بذر و تنش شورى و معرفى بهترين مدل ركرسيون غيرخطى با استفاده از شاخصهاى سنجش

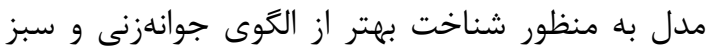
شدن اين كَياه انجام يذيرفت.

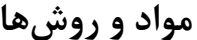
آزمايش حاضر با به كارگيرى دو فاكتور شامل تنش

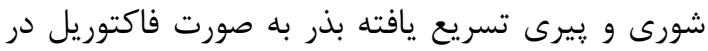

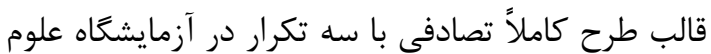

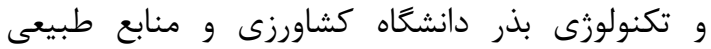
خوزستان در سال ^وس إنجام شد. در ابتدا جوانهزنى

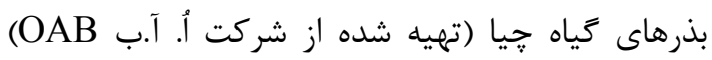

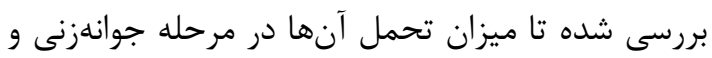
رشد كياهجه، نسبت به تنش شورى (صفر، •له، ..1.

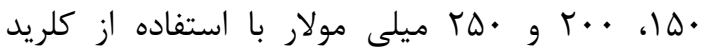

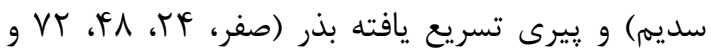

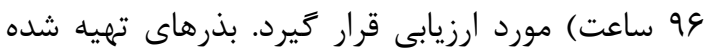

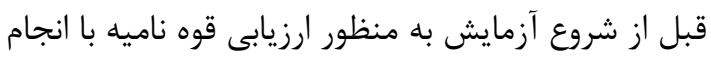

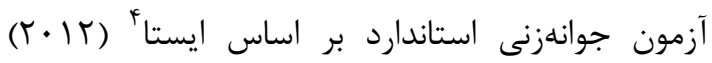

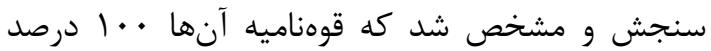

\footnotetext{
Guiotto

${ }^{2}$ Iglesias-Puig and Haros

${ }^{3}$ Scheer

${ }^{4}$ ISTA
} 
ץ- سرعت جوانهزنى (GR) با استفاده از رابطه F

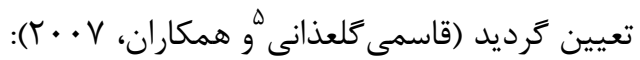
GR $=\frac{1}{\text { MGT }}$ F- متوسط جوانهزنى روزانه (MDG) كه شاخصى از سرعت جوانهزنى روزانه است از رابطه ه محاسبه شد

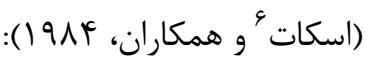
$\mathrm{MDG}=\frac{\boldsymbol{F G P}}{\boldsymbol{d}}$ رابطه ه: در اين رابطه FGP درصد جوانهزنى نهايى (قوه ناميه) و d تعداد روز تا رسيدن به حداكثر جوانهزنى

$$
\text { نهايى (طول دوره آزمايش) است. }
$$

ه- ضريب سرعت جوانهزنى (CVG) كه مشخصه

سرعت و شتاب جوانهزنى بذر است كه از رابطه 9

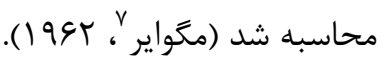
رابطه 9:

$$
\mathrm{CVG}=\frac{G 1+G 2+G 3+\cdots \ldots+G n}{(1 \times G 1)+(2 \times G 2)+(3 \times G 3)+\cdots \ldots+(n \times G n)}
$$
تعداد بذرهاى جوانهزده از روز اول تا روز

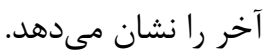

צ- شاخص سرعت جوانهزنى (GRI) طبق فرمول

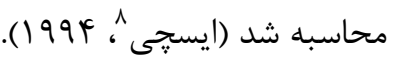

رابطه V:

$$
\mathrm{GRI}=\frac{G 1}{1}++\ldots \ldots . .+\frac{G n}{n} \frac{G 2}{2}
$$$$
\text { كه G1، G2 G2 به ترتيب تعداد بذرهاى }
$$

$$
\text { جوانهزده در روز اول، دوم و روز n ام هستند. }
$$

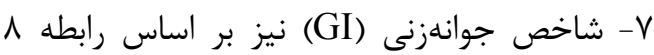

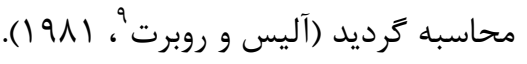

GI $=(10 \times n 1)+(9 \times n 2)+\ldots \ldots(1 \times n 10):$ رابطه 1 (

=gn آخرين روزى كه تمام بذرها جوانه زدند = ni

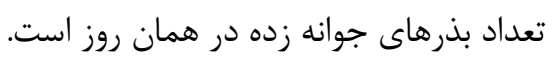

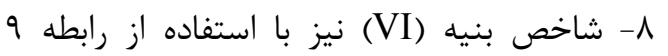

محاسبه شد كه در آن VI شاخص بنيه، Ls ميانكين طول ساقهجه (ميلىمتر) و Pg درصد جوانهزنى كل در

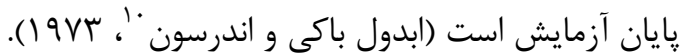
$\mathrm{VI}=\frac{\boldsymbol{I S} \times \boldsymbol{P g}}{\mathbf{1 0 0}}$ رابطه 9:

\footnotetext{
${ }^{5}$ Ghasemi Golazani

${ }^{6} \mathrm{Scott}$

${ }^{7}$ Maguire

${ }^{8}$ Esechie

${ }^{9}$ Ellis and Roberts

${ }^{10}$ Abdul-Baki and Anderson
}

• م ميلى مولار) و براى تيمار شاهد ه ميلىليتر آب

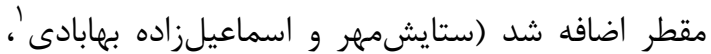
( 1 .

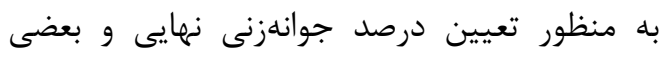
ويزگى هاى مرتبط، بذرهاى جداسازى شده مورد نظر در

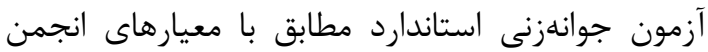

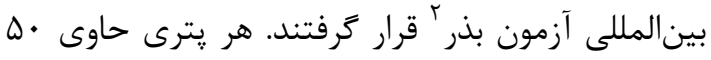
عدد بذر بود و شمارش بذرهاى جوانهزده به صوريه صورت

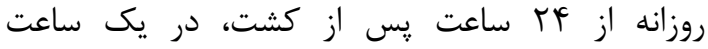

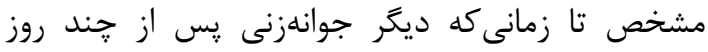

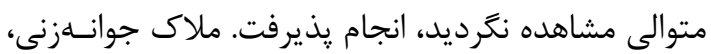

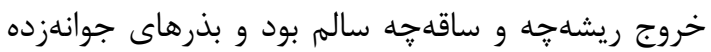

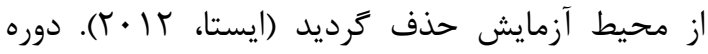

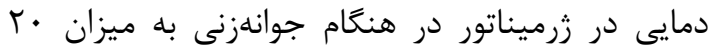

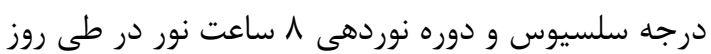

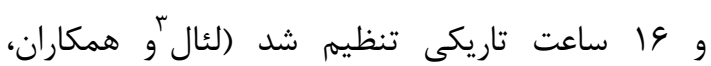

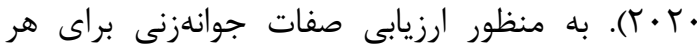

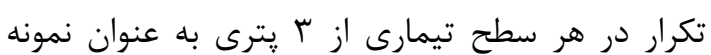

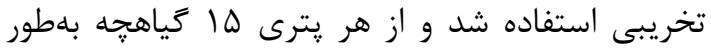
تصادفى انتخاب شده و صفات طول ريشه خه و ساقهجه

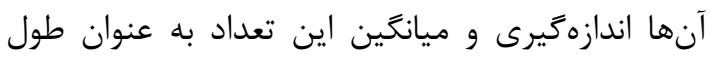

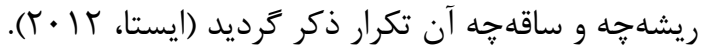
اندازهيرى برخى از شاخصهاى جوانهزنى مرتبط با

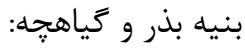
ا- درصد جوانهزنى نهايى (FGP) از تعداد بذرهاى جوانهزده تقسيم بر تعداد بذرهاى كشت شده و ضربدر

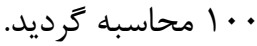
r- متوسط زمان لازم براى جوانهزنى (MGT) كه شاخصى از سرعت و درصد جوانهزنى است، از رابطه 1

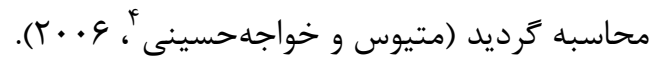
MGT $=\frac{\sum(\mathbf{n d})}{\sum \boldsymbol{n}}$ كه در اين رابطه: n= تعداد بذرهاى جوانهزده در

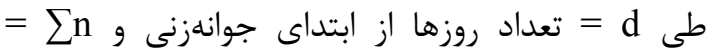
تعدادكل بذرهاى جوانه زده است.

\footnotetext{
${ }^{1}$ Setayesh Mehr and Esmaeilzadeh Bahabadi

${ }^{2}$ ISTA: International Seed Testing Association ${ }^{3}$ Leal

${ }^{4}$ Matthews and Khajeh-Hosseini
} 


$$
\begin{aligned}
& \text { RMSE }=\sqrt{\frac{\sum_{\mathbf{i}=\mathbf{1}}^{\mathbf{n}(\mathbf{P t}-\mathbf{0 t})^{2}}}{\mathbf{n}}} \quad: \quad \text { ا } \\
& \mathrm{R}_{\text {Adj }}^{2}=1-\frac{\sum(\boldsymbol{O} t-\boldsymbol{P} t)^{2}}{(\boldsymbol{O} t-\overline{0} t)^{2}} \quad 19 \text { رابطه }
\end{aligned}
$$$$
\text { كه در اين دو رابطه Ot و Pt به ترتيب مقادير }
$$$$
\text { اندازهيرى شده و ييشبينى شده و و }
$$$$
\text { مشاهدات مىباشد. RMSE كمتر به معنى برازش }
$$$$
\text { مناسبتر مدل بوده و R2 Adj توصيفى از قابليت }
$$

ييشبينى مدل را ارائه مى كند كه عدد نزديكتر به يكى نيز نشانگر برازش بهتر مدل به رانه دادهها مىباشد.

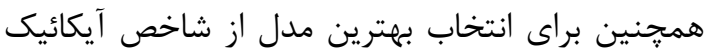
تصحيحشده (در آزمايشهايى كه تعداد نقاط يا نمونهها AIC كم است از شاخص AICc (n) استفاده مى ₹ردد) نيز استفاده خرديد. رابطه VICc=AIC + $\mathrm{AIC}=\mathrm{n} \times \operatorname{Ln}\left(\frac{\mathbf{R S S}}{\mathrm{n}}\right)+2 \mathrm{k}$ )

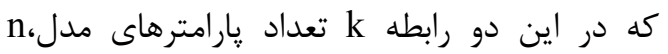

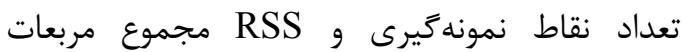

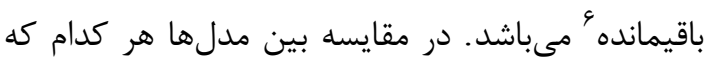
مقدار AICc كمتر يا منفى مترى داشته باشند به عنوان

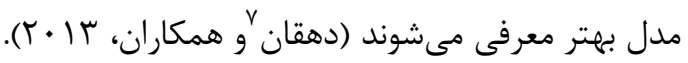

\section{محاسبات آمارى}

قبل از انجام محاسبات آمارى آزمون نرمال بودن

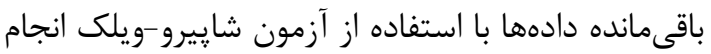
كرفت كه نشان داد كليه دادهها از لحاظ آمارى نرمال مىباشند. تجزيه واريانس دادهها بوسيله نرم افزار 9.3

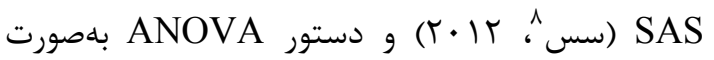
مدل آزمايش فاكتوريل در قالب طرح كاملاً تصادفى با بات سه تكرار انجام شد. ميانكَينها با آزمون LSD در سطح

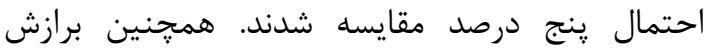
منحنىها و رسم شكلها با كمك نرمافزارهاى د14 SigmaPlot انجام شد. در ضمن با توجه به معنى بدار بودن اثر متقابل فاكتورهاى مورد بررسى برشدهيى اثرات متقابل در هر سطح ييرى تسريع يافته بذر با استفاده از

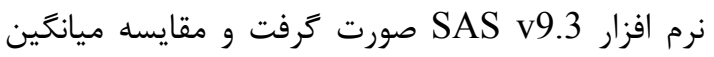

\footnotetext{
${ }^{6}$ The residual sums of squares ${ }^{7}$ Dehghan

${ }^{8} \mathrm{SAS}$
}

مدلهاى مورد استفاده

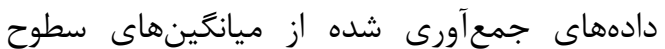
شورى در هر سطح زيرى تسريع يافته بذر بـراى يـيشبينى برخى خصوصيات جوانهزنى و براى ساخت و ارزيابى مدلهاى غير خطى تجربى مورد استفاده قرار

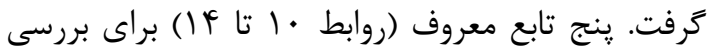
خصوصيات جوانهزنى گياه جيا در برابر شورى مورد

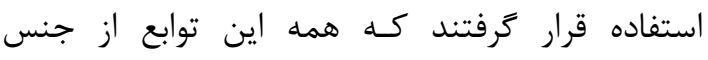
مدلهاى سيخموئيدى و جندجملهاى هستند كه بـسته بـه شرايط، در توصيف روند جوانهزنى، نقاط قوت يا ضعف مخصوص به خود را دارا هستند:

$y=a / 1+\exp ^{(-b(x-x 0))}$ تابع لوجستيك ؛

$y=a \exp ^{(-\exp (-b(x-x 0))}$ رابطه - : تابع كامبرتز ' رابطه ابع اهبرئ

$y=a / 1+\exp ^{(-(x-x 0) / b))}$ تابع سيخموئيد": رابطه بابع سيخموي تابع درجه r' $y=a+b x+c x^{2}$ رابطه سا: تابع درجه سه: $y=a+b x+c x^{2}+d x^{3} \quad$ رابطه كه در اين مدلها y لشاندهنده شاخصهاى جوانهزنى مرتبط با بنيه بذر و زياهجه گياه جيا، نشانَر سطوح شورى، a بيانگر مجانـب بالاى منحنى يا همان حداكثر مقدار شاخصهاى جوانهزنى مرتبط بان

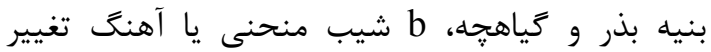
صفت مورد بررسى به ازاى هر سطح شورى،X0 سطحى

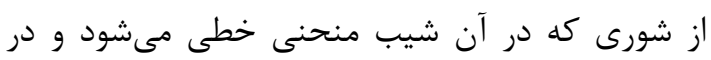

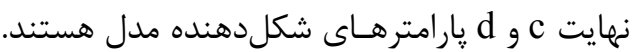

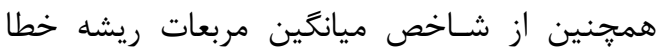
و ضريب دقت انـدازهزيـرى (RMSE) ها و \&1) به منظور ارزيابى در دقت برازش مدلهـا استفاده گرديد

\footnotetext{
${ }^{1}$ Logistic

2 Gompertz

${ }^{3}$ Sigmoid

${ }^{4}$ Quadratic

${ }^{5}$ Cubic
} 
در برابر شورى تا سطح · ․ ميلىمولار در شرايط عدم

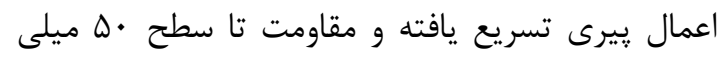

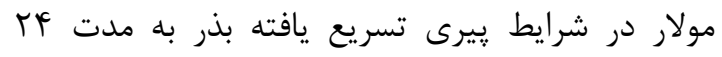

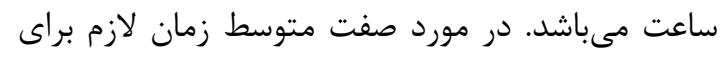

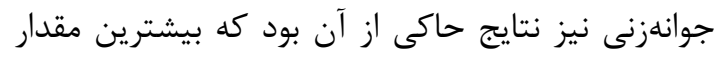

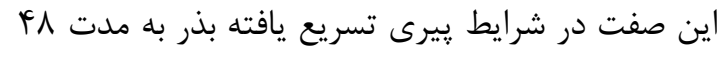

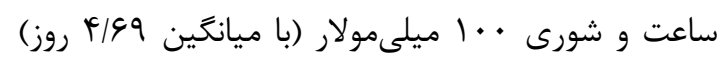

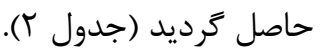
نتايج برازش مدلهاى مورد مطالعه نشان داد كاد كه

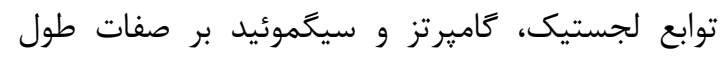
ريشه קه، طول ساقهجه، درصد جوانهزنى نهايى، ميانكًين جوانهزنى روزانه، شاخص سرعت جوانهزنى و شاخص

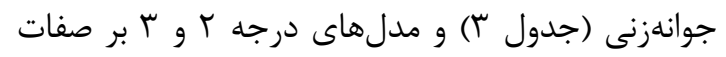

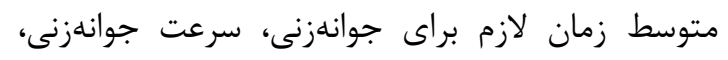

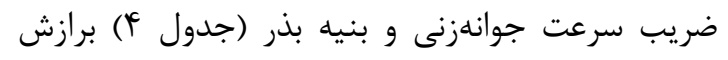
مناسبترى داشتند، سيس انتخاب بهترين مدل براى هر

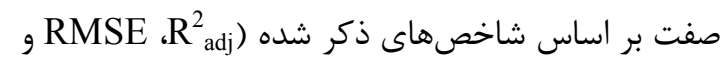
(AICc ) انجام شد.

در مورد صفات طول ريشهجه، طول ساقهجه، درصد

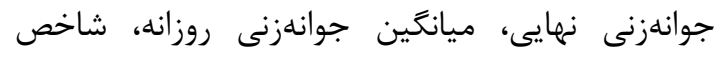

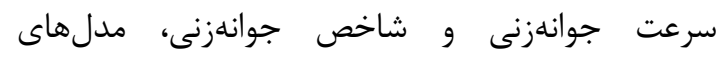

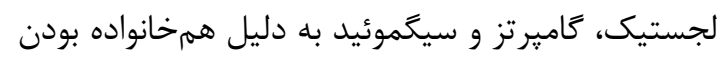

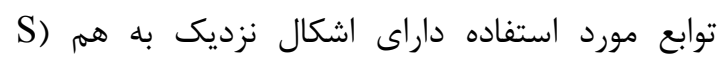

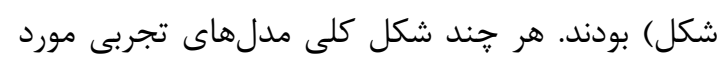

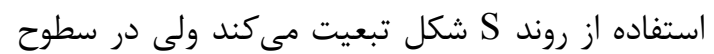

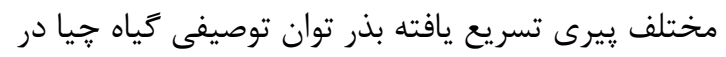
ياسخ به سطوح شورى متفاوت بود.
سطوح شورى و رتبهبندى آنها در هر سطح تيمار يِيرى

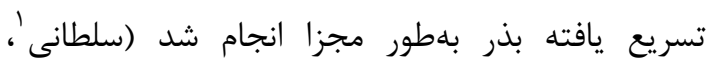
$(Y \cdot V$

\section{نتايج و بحث}

نتايج (جدول (1) نشان داد كه برهمكنش بين

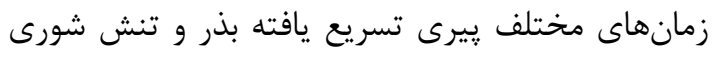

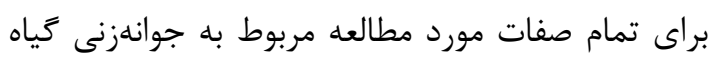
جيا معنى دار بود. با توجه به نتايج، بهجز صفت متودا بود زبن زمان لازم براى

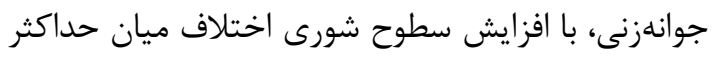

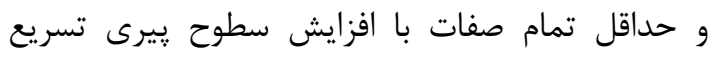

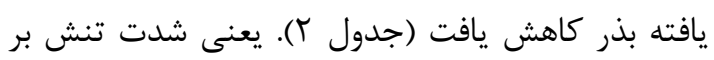

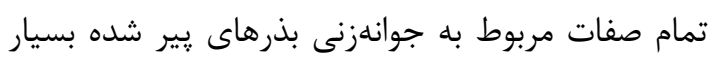

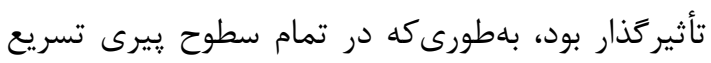

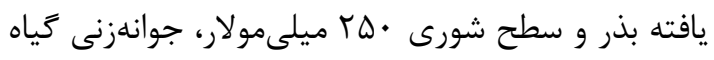

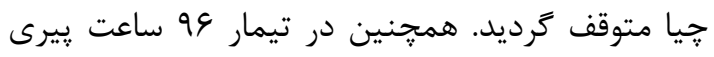

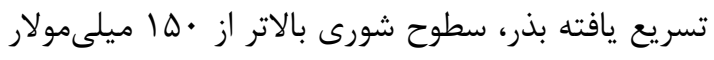

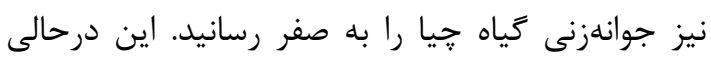

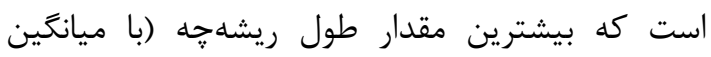

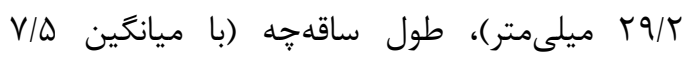

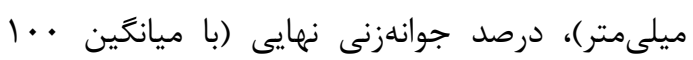

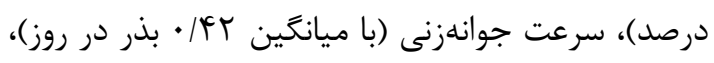

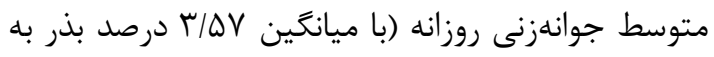

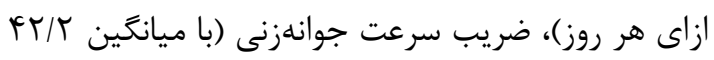

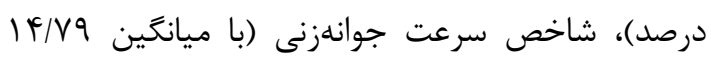

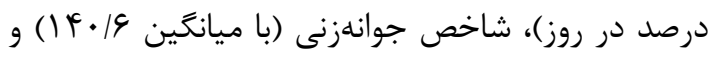

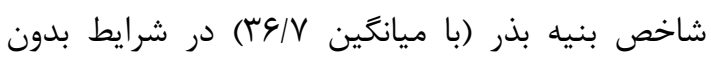
ييرى تسريع يافته و عدم اعمال شورى حاصل ترديد.

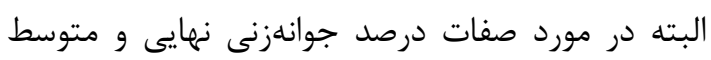

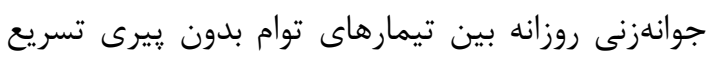

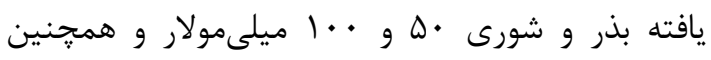

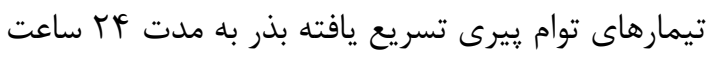

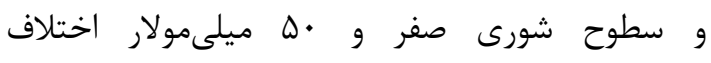

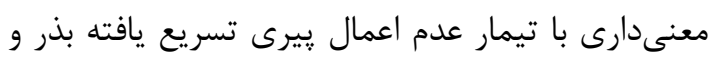

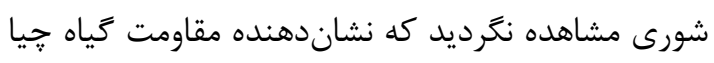

\footnotetext{
${ }^{1}$ Soltani
} 


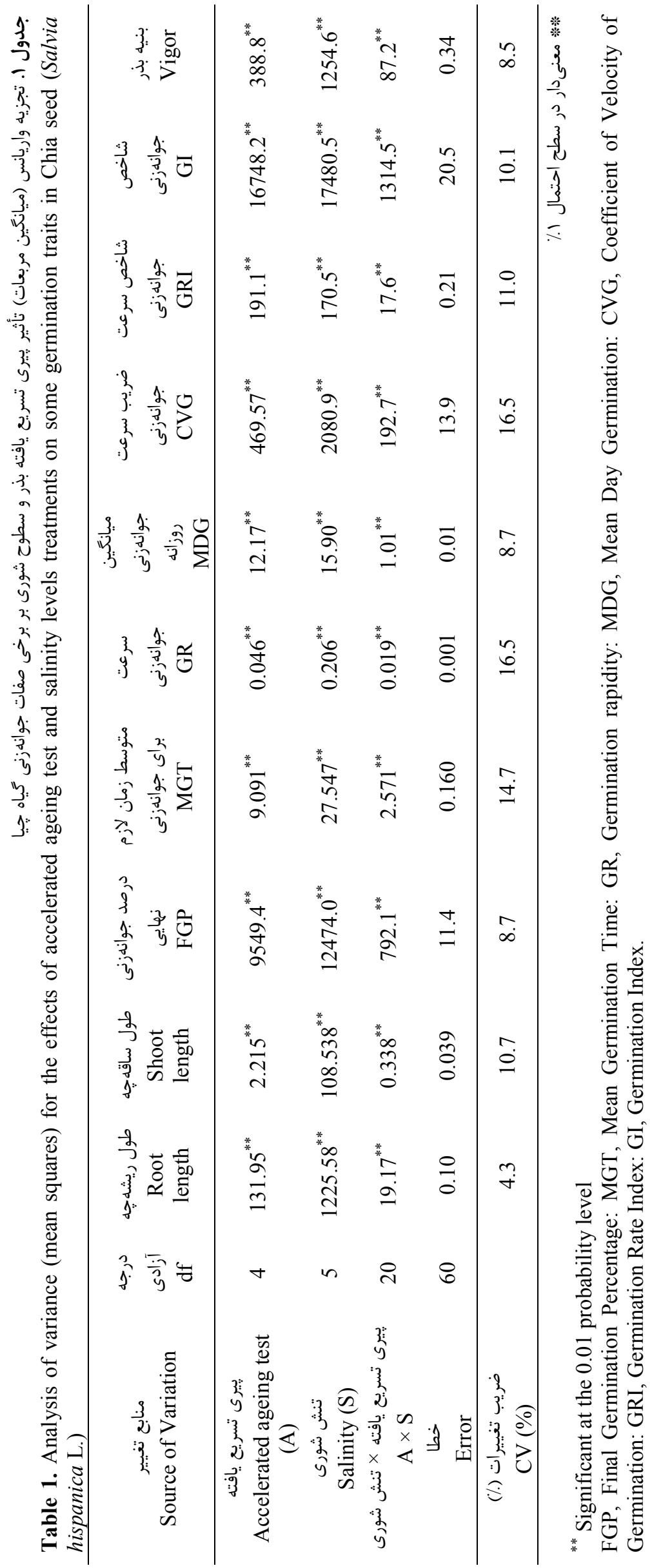




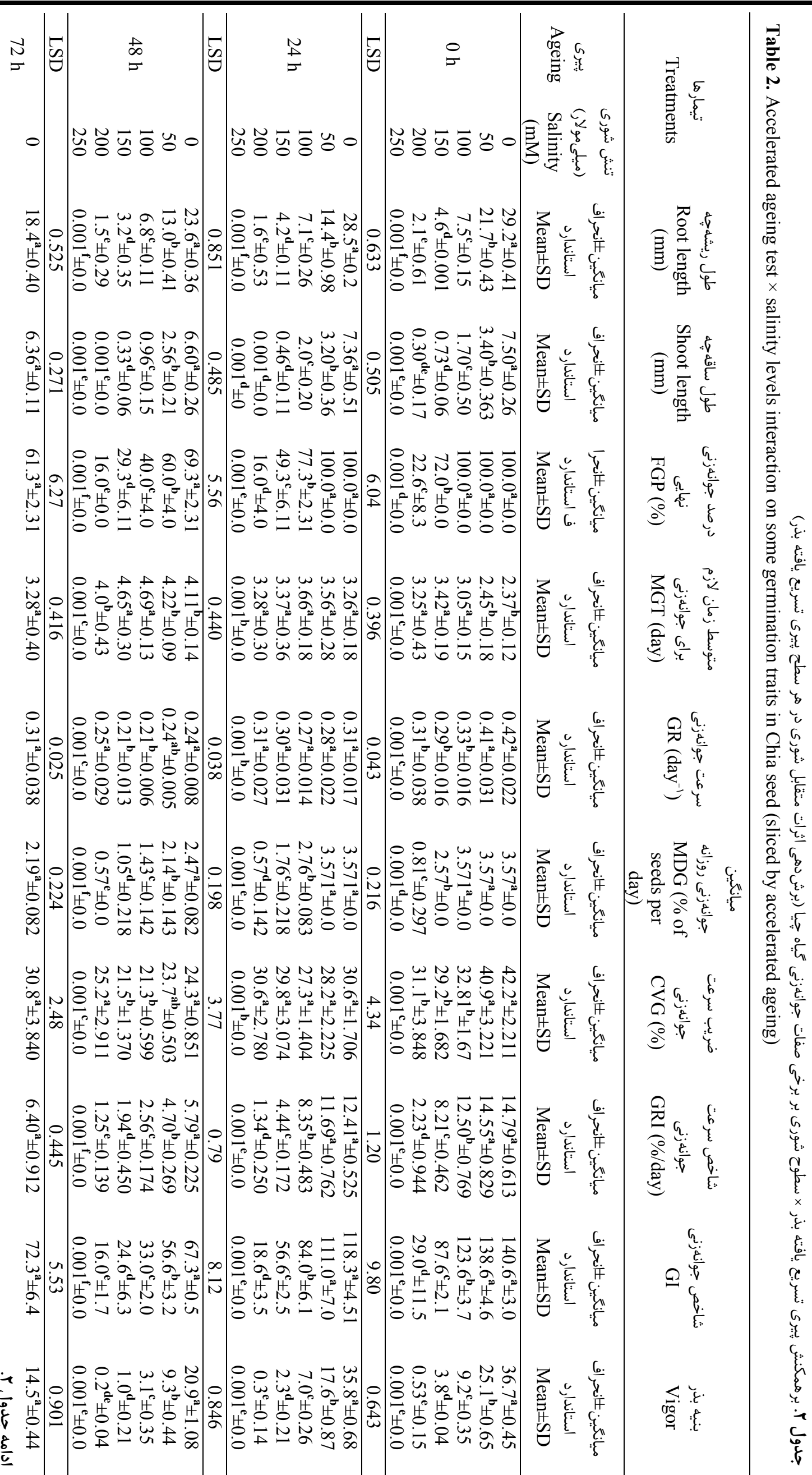




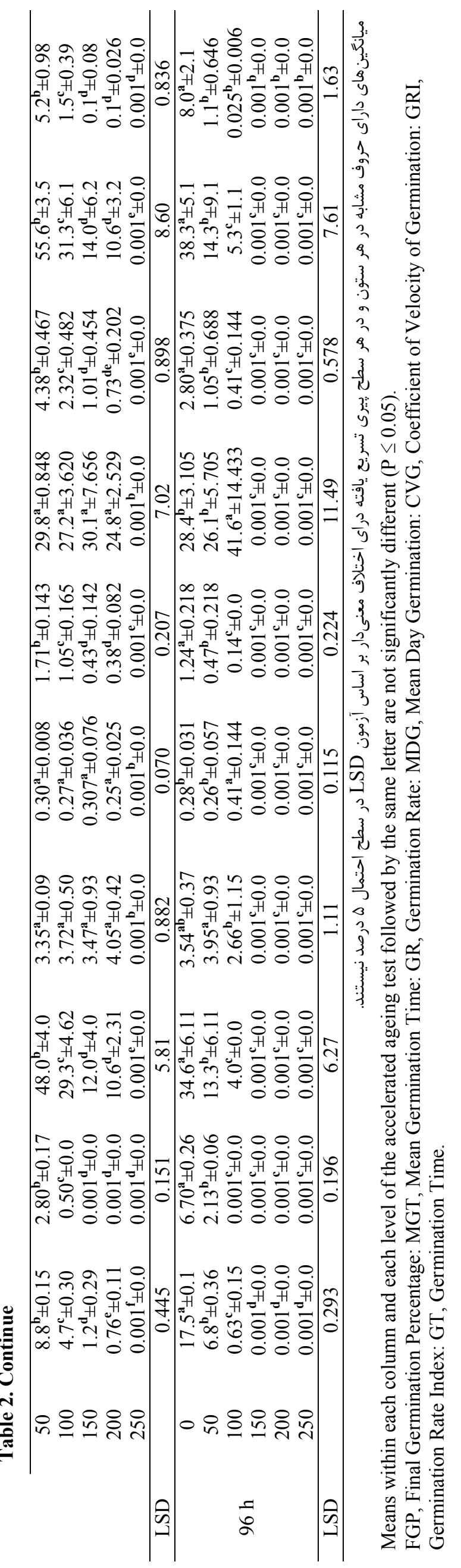




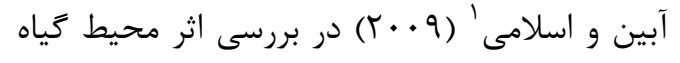

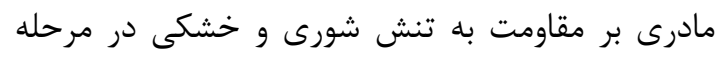

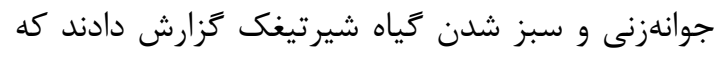

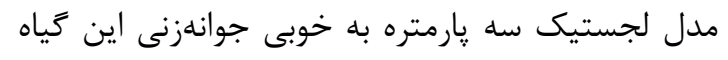

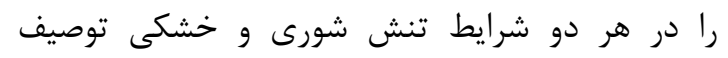

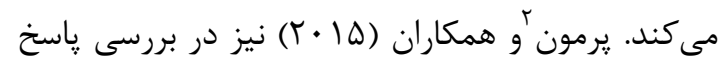

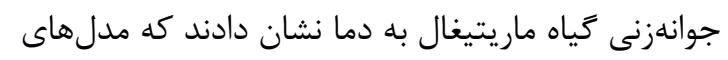

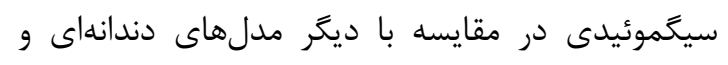

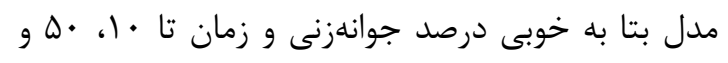

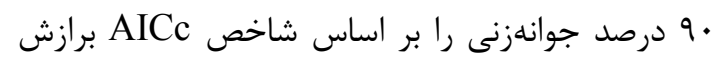

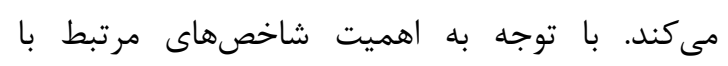

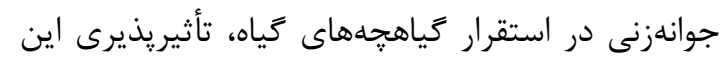
شاخص از طريق مدلهاى سيخموئيدى سه ديارامتره

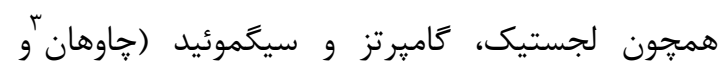

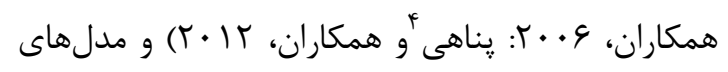

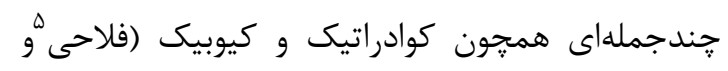

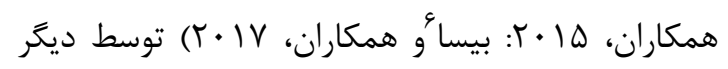

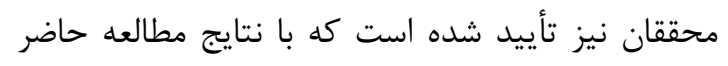

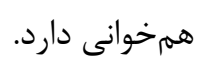
نتايج حاصل از كاهش • • درصد هركدام از صفات

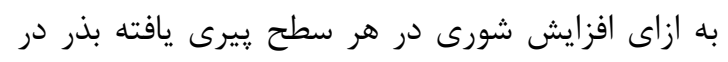

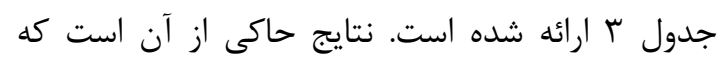

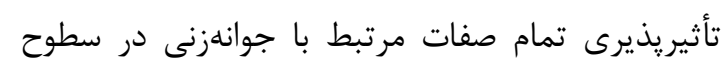

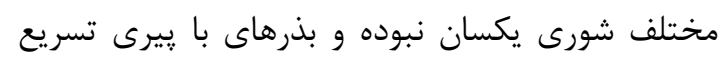

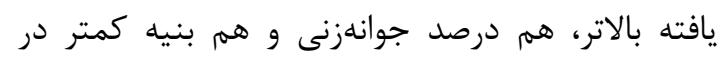

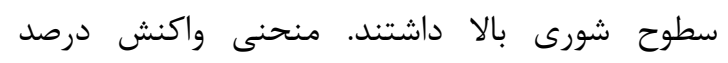
جوانهزنى نهايى نسبت به سطوح شورى در كليه سطوح

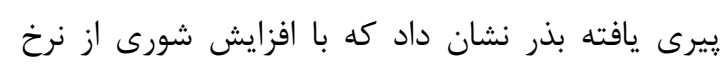

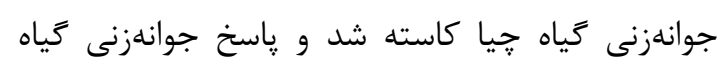

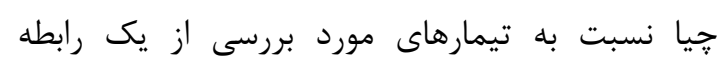

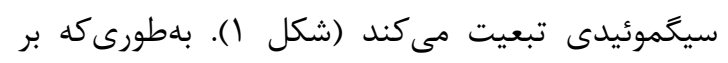

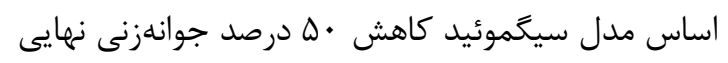

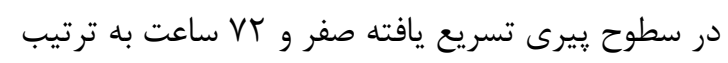

\section{${ }^{1}$ Abin and Eslami}

${ }^{2}$ Parmoon

${ }^{3}$ Chauhan

${ }_{5}^{4}$ Panahi

${ }^{5}$ Fallahi

${ }^{6}$ Bessa
در همين راستا نتايج حاصل از شاخصهاى سنجش

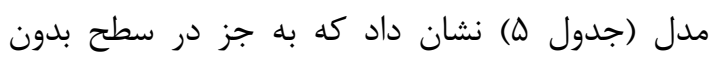

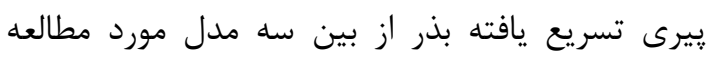

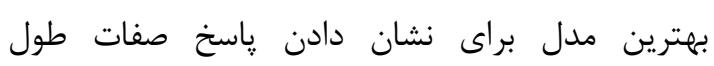

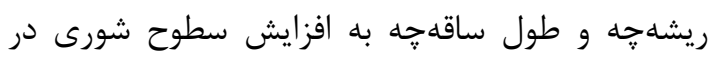

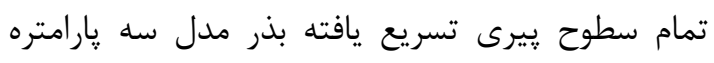

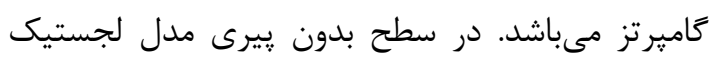

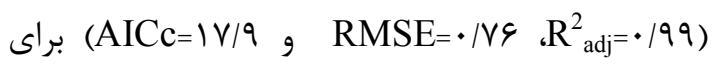
صفت طول ريشهجه و مدل سيخموئيد (A9) RMSE=•/ / 9 بهترين برازش را ارائه مىدهند. در مورد صفات درصد

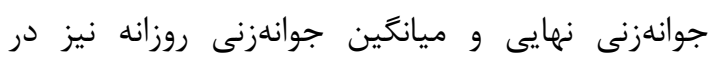

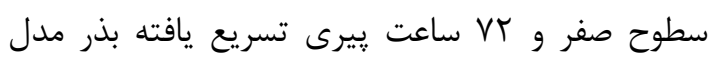

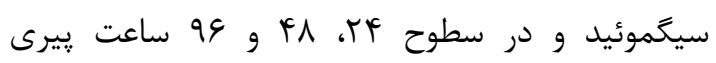

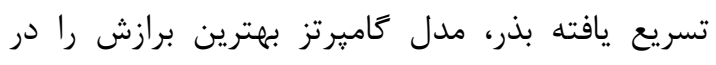

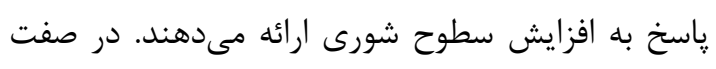

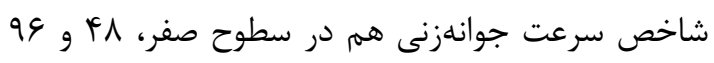
ساعت يِرى تسريع يافته بذر مدل گاميرتز

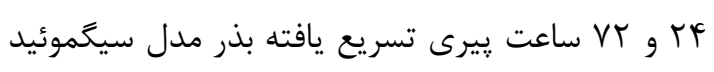

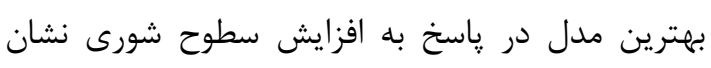

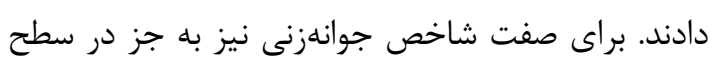

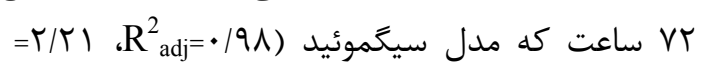
RMSE

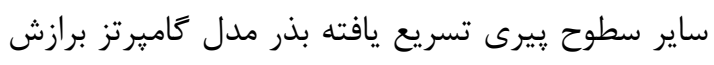
مناسبترى براى ياسخ به افزايش سطوح شورى دئ در كياه

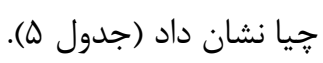

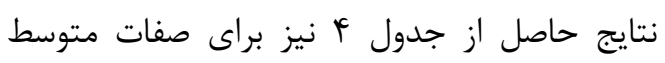

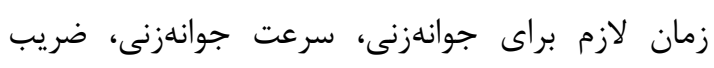

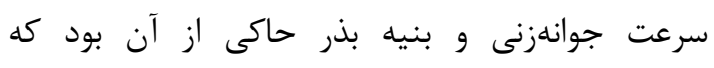

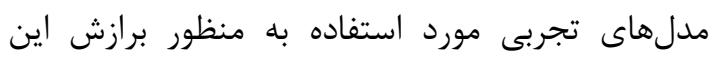

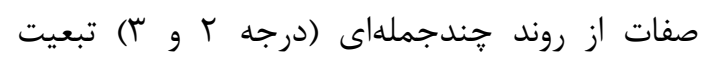

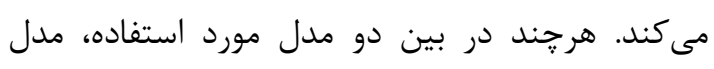

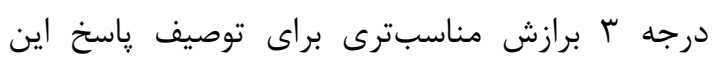

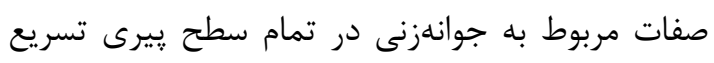
يافته بذر و شورى داشت (جدول 9). 
شد. در اين رابطه محققان اظهار داشتند كه كيفيت بذر از دو طريق مستقيم (اثر بر رشد) و غيرمستقيم (كاهش ائل

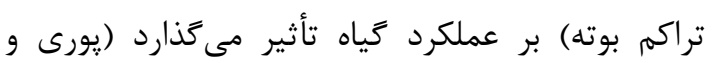

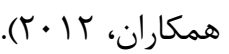
كاهش كيفيت بذر از طريق ييرى تسريع يافته منجر به برخى تغييرات در ساختار مولكولى اسيدهاى

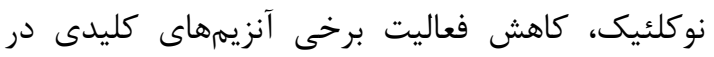

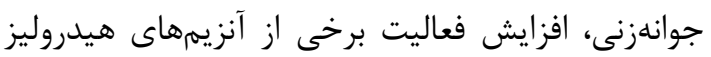

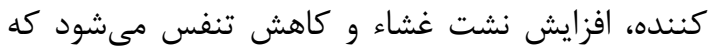
در نتيجه اين تغييرات، بنيه بذر كاهش يافته و منجر به

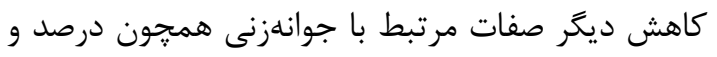
سرعت جوانهزنى و رشد كياهجه مى كردد كه نتيجه اين امر كاهش توانايى جوانهزنى بذرها تحت شرايط تنشزان

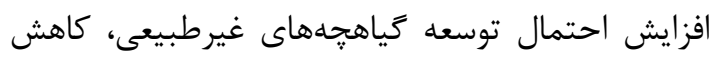
درصد استقرار بوته در مزرعه و در نهايت كاهش عملكرد

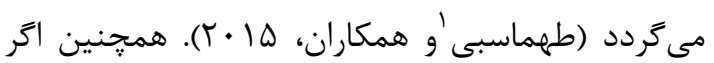
شدت پيرى زياد باشد ممكن است هيج بذرى جوانه نزند.

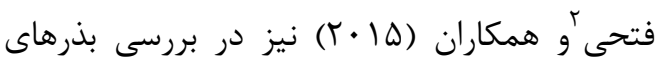
ييرى تسريع يافته كَاهان ينيرك، سوروف و قياق تحت

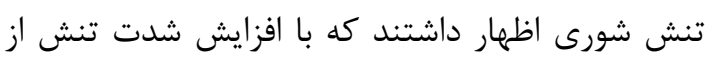
صفر به T ا دسىزيمنس تمام صفات مورد مطالعه اعم از سرعت جوانهزنى، يكنواختى جوانهزنى، درصد و شاخص

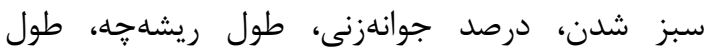

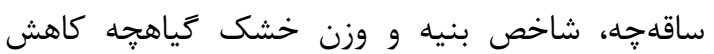
يافت. همجنين آنها بيان داشتند كه پِيرى تسريع يافته

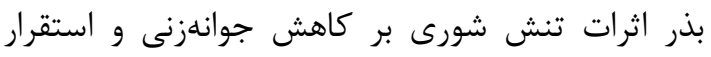

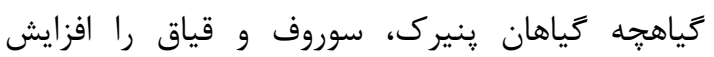
مى دهد.

\footnotetext{
${ }^{1}$ Tahmasbi

${ }^{2}$ Fatahi
}

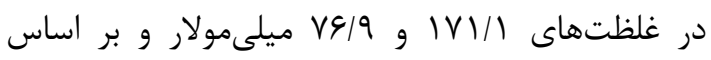
مدل كاميرتز كاهش •له درصد جوانهزنى نهايى در

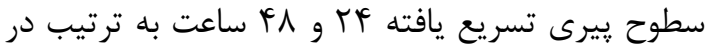

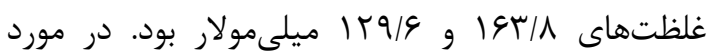
بنيه بذر نيز برازش مدل جندجملهاى درجه ب نشان داد كه با افزايش سطوح شورى در تمام سطوح يبرى يافته بذر قدرت سبز شدن كياهجه جيا كاهش مى يابد كه شيب كاهش در سطوح كمتر يِرى يافته بذر شديدتر

اختلاف ميان حداكثر و حداقل صفات بين سطوح شورى در تيمار شاهد بيشترين و در ييرى تسريع يافته

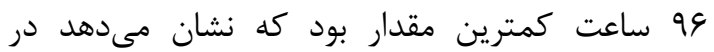

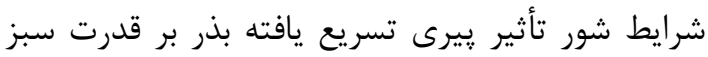

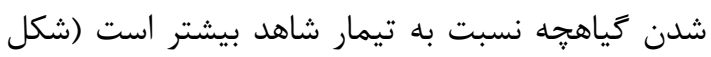

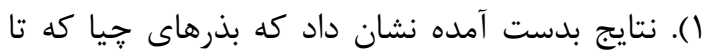

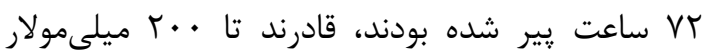

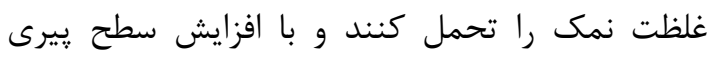

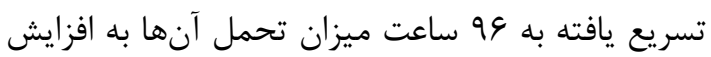
سطح شورى كاسته شد و بذرها دجار آسيب شديد إندان شند. تأثير توام تنش شورى و ويرى تسريع يافته بذر از طريق برهم زدن سازوكارهاى مرتبط با جوانهزنى و كاهش فعاليت آنزيمهاى دخيل در اين فرآيند موجب

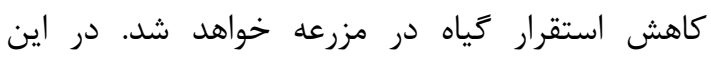
خصوص محققان اظهار داشتند كه تنشهاى محيطى مىتواند از طريق كاهش درصد و سرعت جوانهزنى بر

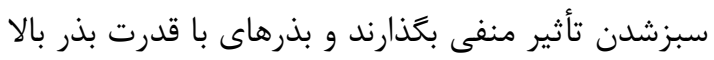

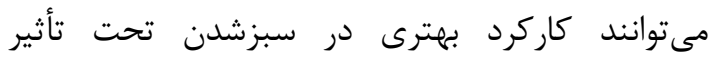

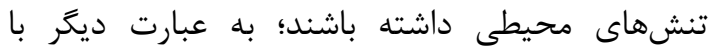
افزايش شدت تنش، بذرهايى با قدرت بالاتر بهتر سبز

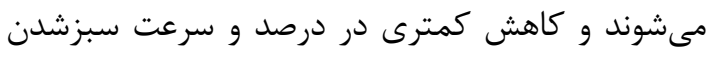

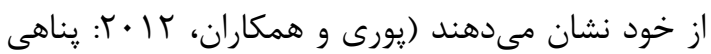

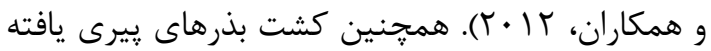

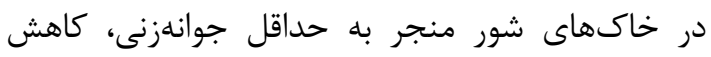
تراكم گياه در واحد سطح و در نهايت كاهش عملكرد

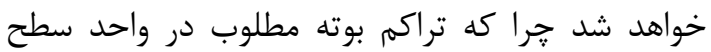

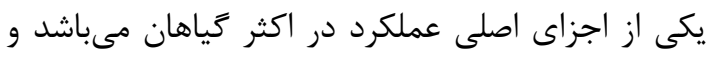

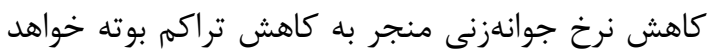









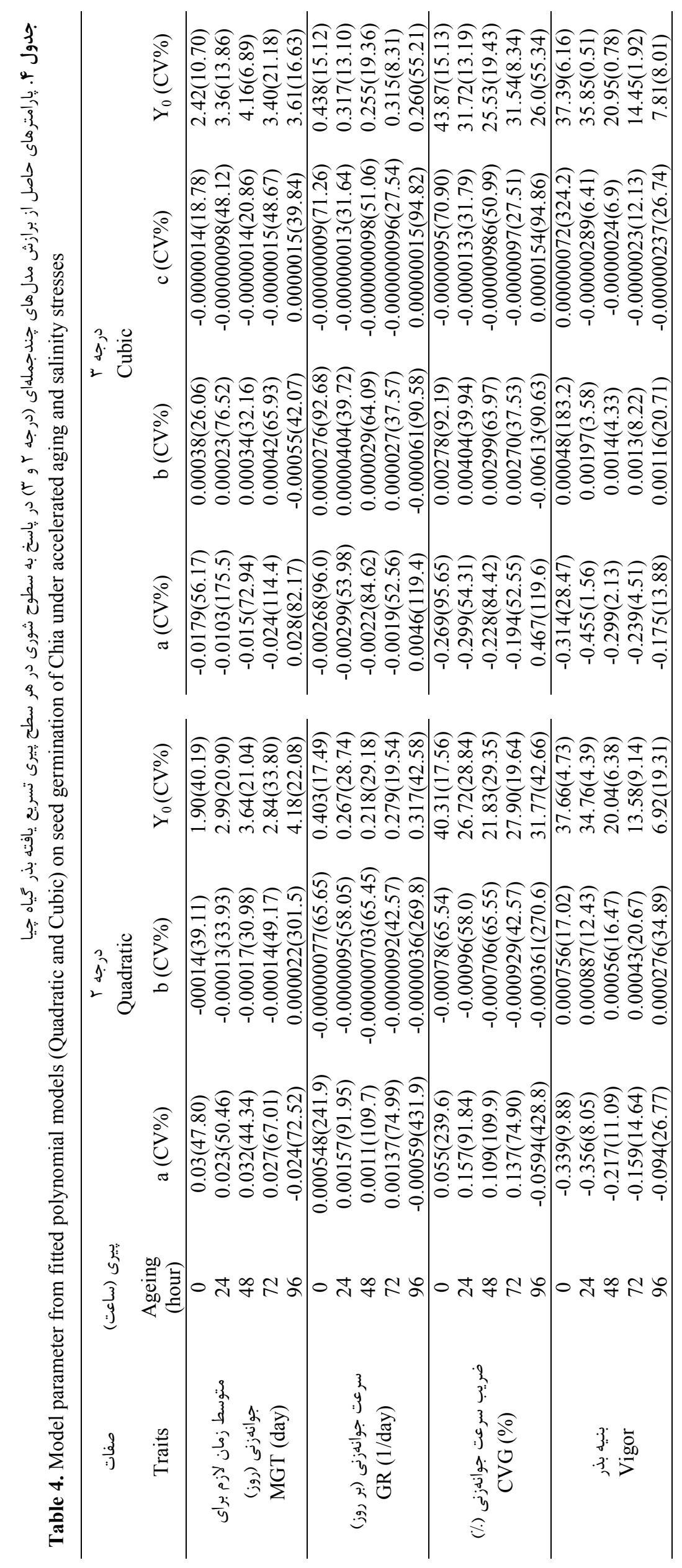




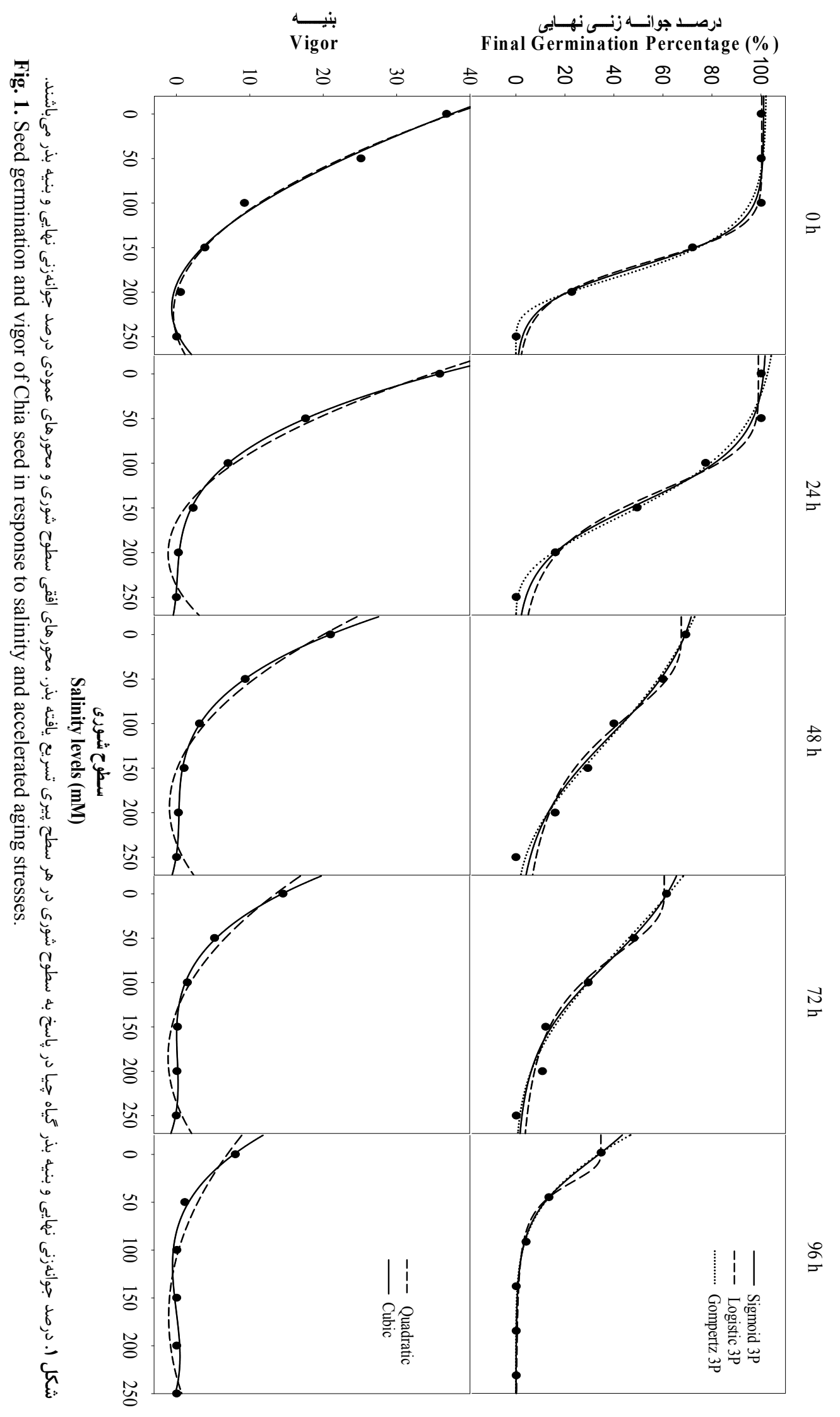


جدول ه. آمارههاى برآورد شده از برازش مدل هاى سيخموئيدى (لجستيك، كاميرتز و سيخموئيد) در باسخ به سطوح بيرى تسريع يافته بذر كياه حيا.

Table 5. Model parameter from fitted sigmoid models (logistic, Gompertz and Sigmoid) on seed germination of Chia under the accelerated aging condition

\begin{tabular}{|c|c|c|c|c|c|c|c|c|c|c|}
\hline \multirow{2}{*}{ صفات } & \multirow{2}{*}{ 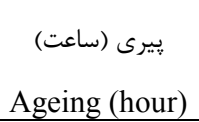 } & \multicolumn{3}{|c|}{$\begin{array}{c}\text { لجستيكى } \\
\text { Logistic 3P }\end{array}$} & \multicolumn{3}{|c|}{$\begin{array}{c}\text { Fاميرتز } \\
\text { Gompertz 3P }\end{array}$} & \multicolumn{3}{|c|}{$\begin{array}{c}\text { سيخموئيد } \\
\text { Sigmoid 3P }\end{array}$} \\
\hline & & RMSE & $\mathrm{R}^{2}$ Adj & $\mathrm{AICc}$ & RMSE & $\mathrm{R}_{\text {Adj }}^{2}$ & $\mathrm{AICc}$ & RMSE & $\mathrm{R}^{2}$ Adj & $\mathrm{AICc}$ \\
\hline \multirow{5}{*}{$\begin{array}{l}\text { طول ريشه } \text { (ميلمىمتر) } \\
\text { Root length (mm) }\end{array}$} & 0 & 0.759 & 0.992 & 44.46 & 1.568 & 0.965 & 53.30 & 1.236 & 0.978 & 50.51 \\
\hline & 24 & 0.747 & 0.990 & 44.51 & 0.452 & 0.996 & 37.86 & 0.456 & 0.996 & 38.01 \\
\hline & 48 & 0.651 & 0.989 & 42.89 & 0.251 & 0.998 & 30.41 & 0.304 & 0.998 & 33.10 \\
\hline & 72 & 0.601 & 0.985 & 41.90 & 0.351 & 0.995 & 35.01 & 0.379 & 0.994 & 36.04 \\
\hline & 96 & 0.108 & 0.999 & 12.13 & 0.087 & 0.999 & -43.62 & 0.078 & 0.999 & -1.47 \\
\hline \multirow{5}{*}{$\begin{array}{l}\text { طول ساقه } \text { (ميلمىمتر) } \\
\text { Shoot length (mm) }\end{array}$} & 0 & 0.179 & 0.992 & 27.39 & 0.099 & 0.998 & 19.13 & 0.091 & 0.998 & 17.93 \\
\hline & 24 & 0.352 & 0.969 & 35.51 & 0.254 & 0.984 & 31.45 & 0.265 & 0.983 & 31.93 \\
\hline & 48 & 0.114 & 0.996 & 21.88 & 0.060 & 0.999 & 10.52 & 0.065 & 0.999 & 12.22 \\
\hline & 72 & 0.063 & 0.999 & 13.54 & 0.030 & 0.999 & -15.39 & 0.036 & 0.999 & 3.76 \\
\hline & 96 & 0.090 & 0.999 & -41.54 & 0.035 & 0.999 & -41.48 & 0.063 & 0.999 & -41.48 \\
\hline \multirow{5}{*}{$\begin{array}{c}\text { درصد جوانهزنى نهايى } \\
\text { FGP (\%) }\end{array}$} & 0 & 1.966 & 0.996 & 56.06 & 2.200 & 0.995 & 57.42 & 1.798 & 0.996 & 54.98 \\
\hline & 24 & 4.37 & 0.979 & 65.72 & 2.36 & 0.994 & 58.27 & 2.85 & 0.991 & 60.54 \\
\hline & 48 & 4.312 & 0.945 & 65.56 & 2.716 & 0.978 & 59.97 & 3.300 & 0.968 & 62.32 \\
\hline & 72 & 2.643 & 0.975 & 59.69 & 2.615 & 0.976 & 59.51 & 2.344 & 0.980 & 58.19 \\
\hline & 96 & 0.641 & 0.995 & 42.49 & 0.354 & 0.999 & 33.12 & 0.430 & 0.998 & 36.69 \\
\hline \multirow{5}{*}{$\begin{array}{c}\text { ميانگين جوانهزنى روزانه } \\
\text { MDG (\% of seeds } \\
\text { per day) }\end{array}$} & 0 & 0.067 & 0.996 & 16.01 & 0.078 & 0.995 & 17.44 & 0.064 & 0.996 & 14.94 \\
\hline & 24 & 0.156 & 0.979 & 25.71 & 0.084 & 0.994 & 18.27 & 0.101 & 0.991 & 20.52 \\
\hline & 48 & 0.153 & 0.946 & 25.55 & 0.096 & 0.978 & 19.95 & 0.117 & 0.968 & 22.30 \\
\hline & 72 & 0.094 & 0.975 & 19.68 & 0.093 & 0.976 & 19.52 & 0.083 & 0.981 & 18.20 \\
\hline & 96 & 0.022 & 0.996 & 2.26 & 0.012 & 0.999 & -7.23 & 0.015 & 0.998 & -3.62 \\
\hline \multirow{5}{*}{$\begin{array}{c}\text { شاخص سرعت جوانهزنى } \text { GRI (\%/day) } \\
\text { GRI }\end{array}$} & 0 & 0.544 & 0.985 & 40.70 & 0.120 & 0.999 & 22.22 & 0.291 & 0.996 & 33.13 \\
\hline & 24 & 0.403 & 0.988 & 37.10 & 0.256 & 0.995 & 31.58 & 0.221 & 0.996 & 29.82 \\
\hline & 48 & 0.330 & 0.954 & 34.69 & 0.306 & 0.960 & 33.78 & 0.314 & 0.958 & 34.09 \\
\hline & 72 & 0.188 & 0.988 & 27.97 & 0.165 & 0.991 & 26.29 & 0.143 & 0.993 & 24.55 \\
\hline & 96 & 0.075 & 0.990 & 16.99 & 0.051 & 0.996 & 11.56 & 0.559 & 0.995 & 12.84 \\
\hline \multirow{5}{*}{ شاخص جوانهزنى } & 0 & 4.826 & 0.987 & 66.90 & 0.818 & 0.999 & 45.07 & 2.816 & 0.995 & 60.38 \\
\hline & 24 & 6.168 & 0.967 & 69.85 & 2.192 & 0.996 & 57.36 & 3.873 & 0.987 & 64.23 \\
\hline & 48 & 4.090 & 0.947 & 64.91 & 3.534 & 0.961 & 63.14 & 3.727 & 0.956 & 63.78 \\
\hline & 72 & 2.458 & 0.985 & 58.82 & 2.607 & 0.983 & 59.46 & 2.214 & 0.988 & 57.50 \\
\hline & 96 & 0.947 & 0.992 & 47.29 & 0.616 & 0.997 & 41.21 & 0.686 & 0.996 & 42.82 \\
\hline
\end{tabular}

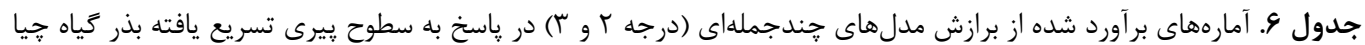

Table 6. Model parameter from fitted polynomial models (Quadratic and Cubic) on seed germination of Chia under the accelerated aging condition

\begin{tabular}{|c|c|c|c|c|c|c|c|}
\hline \multirow{3}{*}{ صفات } & \multirow{3}{*}{ 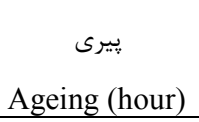 } & \multicolumn{3}{|c|}{ درجه r } & \multicolumn{3}{|c|}{ درجه r } \\
\hline & & & Ouadratic & & & Cubic & \\
\hline & & RMSE & $\mathrm{R}^{2} \mathrm{Adj}$ & $\mathrm{AICc}$ & RMSE & $\mathrm{R}^{2}$ Adi & $\mathrm{AICc}$ \\
\hline \multirow{5}{*}{ متوسط زمان لازم براى جوانهزنى (روز) } & 0 & 0.596 & 0.553 & 41.79 & 0.153 & 0.956 & -12.53 \\
\hline & 24 & 0.488 & 0.760 & 39.39 & 0.275 & 0.886 & -5.51 \\
\hline & 48 & 0.598 & 0.777 & 41.83 & 0.169 & 0.973 & -11.32 \\
\hline & 72 & 0.750 & 0.491 & 44.55 & 0.425 & 0.754 & -0.26 \\
\hline & 96 & 0.721 & 0.713 & 44.06 & 0.354 & 0.896 & -2.47 \\
\hline \multirow{5}{*}{$\begin{array}{l}\text { سرعت جوانهزنى (بر روز) } \\
\text { GR (1/day) }\end{array}$} & 0 & 0.055 & 0.741 & 13.20 & 0.039 & 0.804 & -28.90 \\
\hline & 24 & 0.060 & 0.502 & 14.23 & 0.024 & 0.875 & -34.51 \\
\hline & 48 & 0.050 & 0.460 & 11.98 & 0.029 & 0.722 & -32.44 \\
\hline & 72 & 0.042 & 0.741 & 10.12 & 0.015 & 0.949 & -40.04 \\
\hline & 96 & 0.105 & 0.335 & 21.01 & 0.085 & 0.359 & -16.63 \\
\hline \multirow{5}{*}{$\begin{array}{c}\text { ضريب سرعت جوانهزنى } \\
\text { CVG (\%) }\end{array}$} & 0 & 5.522 & 0.741 & 68.50 & 3.912 & 0.805 & 26.36 \\
\hline & 24 & 6.011 & 0.503 & 69.52 & 2.468 & 0.875 & 20.83 \\
\hline & 48 & 4.998 & 0.459 & 67.31 & 2.924 & 0.722 & 22.87 \\
\hline & 72 & 4.275 & 0.741 & 65.43 & 1.552 & 0.949 & 15.26 \\
\hline & 96 & 10.575 & 0.336 & 76.30 & 8.480 & 0.360 & 35.65 \\
\hline \multirow{5}{*}{ 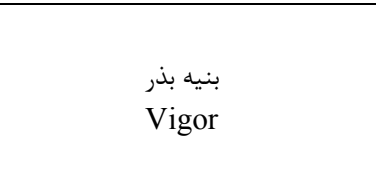 } & 0 & 1.398 & 0.983 & 51.96 & 1.366 & 0.975 & 13.68 \\
\hline & 24 & 1.201 & 0.986 & 50.10 & 0.205 & 0.999 & -16.74 \\
\hline & 48 & 1.002 & 0.970 & 47.98 & 0.148 & 0.999 & -17.98 \\
\hline & 72 & 0.971 & 0.943 & 47.61 & 0.186 & 0.997 & -11.71 \\
\hline & 96 & 1.043 & 0.788 & 48.50 & 0.374 & 0.960 & -1.97 \\
\hline
\end{tabular}




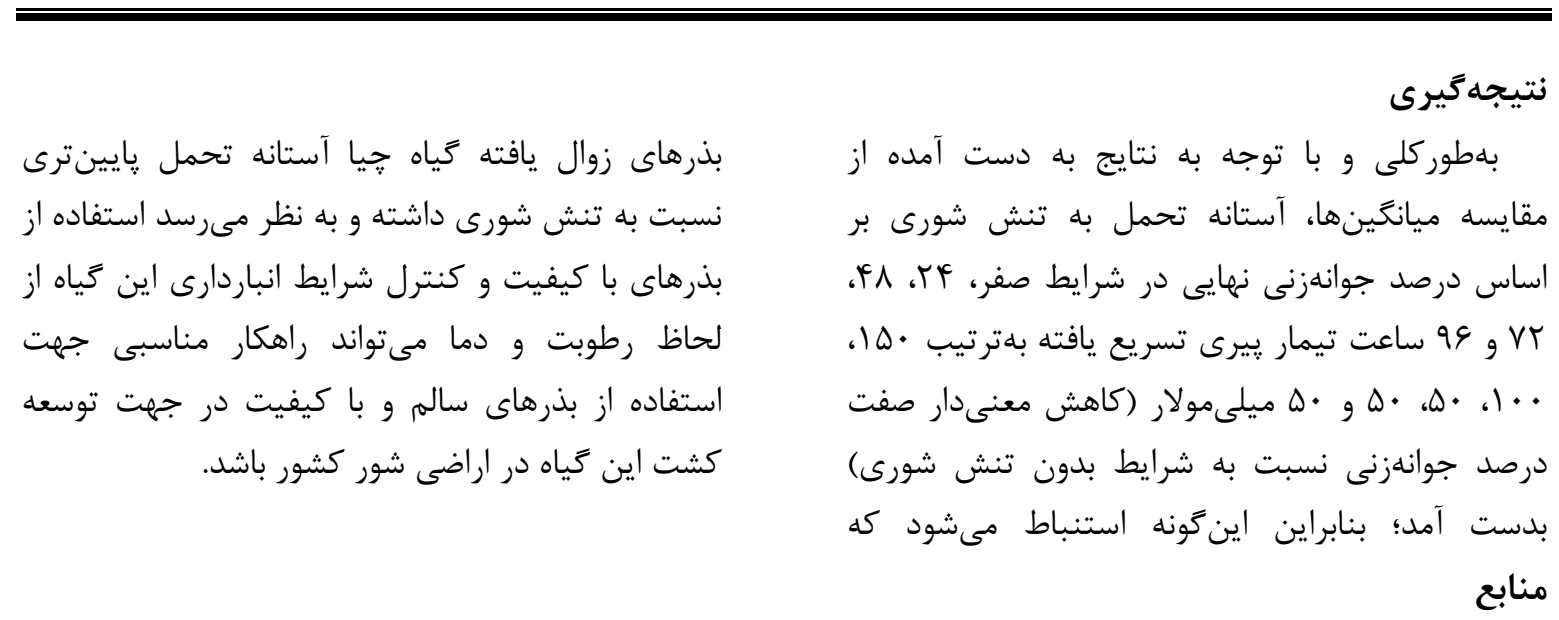

Abdul-Baki, A.A. and Anderson, J.D. 1973. Vigour determination of soybean seed by multiple $\begin{array}{llll}\text { criteria. } & \text { Crop } & \text { 630-633. }\end{array}$ https://doi.org/10.2135/cropsci1973.0011183X001300060013x

Abin, A. and Eslami, S.V. 2009. Influence of maternal environment on salinity and drought tolerance of annual sow thistle (Sonchus oleraceus L.) at germination and emergence stage. Weed Research Journal, 1(2): 1-12. [In Persian with English Summary].

Almansouri, M., Kinet, J.M. and Lutts, S. 2001. Effect of salt and osmotic stresses on germination in durum wheat (Triticum durum Desf.). Plant and Soil, 231(2): 243-254. https://doi.org/10.1023/A:1010378409663

Basra, S.M.A., Ahmad, N., Khan, M.M., Iqbal, N. and Cheema, M.A. 2003. Assessment of cottonseed deterioration during accelerated ageing. Seed Science and Technology, 31(3): 531540. https://doi.org/10.15258/sst.2003.31.3.02

Bessa, M.C., Lacerda, C.F., Amorim, A.V., Bezerra, A.M.E. and Lima, A.D. 2017. Mechanisms of salt tolerance in seedlings of six woody native species of the Brazilian semi-arid. Revista Ciência Agronômica, 48(1): 157-165. https://doi.org/10.5935/1806-6690.20170018

Bradford, M.M. 1976. A rapid and sensitive method for the quantitation of microgram Quan-and Stimulation of 13. Widholm. M. dye binding. Analytical Biochemistry, 72(2487): 254. https://doi.org/10.1016/0003-2697(76)90527-3

Chauhan, B.S., Gill,G. and Preston, C. 2006. Influence of environmental factors on seed germination and seedling emergence of Oriental mustard (Sisymbrium orientale). Weed Science, 54(6): 1025-1031. https://doi.org/10.1614/WS-06-092.1 ; https://doi.org/10.1614/WS06-087R.1

Copeland, L.O. and McDonald, M.B. 2001. Principles of Seed Science and Technology. Dordrecht. The Netherlands: Kluwer Academic Publishers, 18-25. https://doi.org/10.1007/978-1-46151619-4

Dehghan, A., Bannayan Awal, M., Khajehossaini, M., Izadi, E. and Mijani, S. 2013. Simulation of emergence pattern of weeds species in corn (Zea mays L.) field based on sigmoidal models. Journal of Plant Protection, 26(4): 457-466. [In Persian with English Summary].

Dell Aquila, A. and Di Turi, M. 1996. The germination response to heat and salt stress in evaluating vigour loss in aged wheat seeds. Seed Science and Technology, 24: 309-319.

Delouche, J.C. and Baskin, C.C. 1973. Accelerated aging techniques for predicting the relative storability of seed lots. Seed Science and Technology, 1: 427-452.

Eisvand, H. and Farajollahi, Z. 2017. Study of seed storability and seed physiological quality of two ecotypes of sage (Salvia officinalis) using AA test. Journal of Plant Production Research. 24(2): 147-151. [In Persian with English Summary]. 
Ellis, R.A. and Roberts, E.H. 1981. The quantification of ageing and survival in orthodox seeds. Seed Science and Technology, 9: 373-409.

Esechie H. 1994. Interaction of salinity and temperature on the germination of sorghum. Journal of Agronomy and Crop Science, 172(3): 194-199. https://doi.org/10.1111/j.1439037X.1994.tb00166.X

Fallahi, H.R., Mohammadi, M., Aghhavani-Shajari, M. and Ranjbar, F. 2015. Determination of germination cardinal temperatures in two basil (Ocimum basilicum L.) cultivars using nonlinear regression models. Journal of Applied Research on Medicinal and Aromatic Plants, 2(4): 140-145. https://doi.org/10.1016/j.jarmap.2015.09.004

Fatahi, G., Hesami, E. and Ardalan, N. 2015. Investigation of salinity and moisture on the germination of weed seeds mallow, barnyard grass and johnson grass in terms of deterioration of seeds. Journal of Weed Ecology, 3(2): 63-79. [In Persian with English Summary].

Ghasemi Golazani, K., Mazloumi-Oskoe, R., Rahimzadeh-Khoeh, F. and Alizadeh, B. 2007. Changes in seed vigor of Phaseolus vulgaris at different stages of maturity under limited irrigation conditions. Agricultural Science, 17(3): 91-99. [In Persian with English Summary].

Guiotto, E.N., Ixtaina, V.Y., Tomás, M.C.M. and Nolasco, S.M. 2013. Moisture-dependent engineering properties of chia (Salvia hispánica L.) seeds. In: Food Industry. Chapter 17. INTECH Publication, 381-397.

Hadian, J., Kohzadi, B., Asadi, M., Shafie Zargar, A.R. and Ghorbanpour, M. 2019. Evaluation of Growth, Yield Characteristics and Oil Components of Two Chia (Salvia hispanica L.) Varieties in Different Planting Dates. Journal of Medicinal Plants, 2: 59-72. [In Persian with English Summary]. https://doi.org/10.29252/jmp.2.70.59

Hajivand Ghassemabadi, F., Eisvand, H. and Akbarpour, O.A. 2018. Evaluation of salinity tolerance of different clover species at germination and seedling stages. Plant Physiology, 8(3): 2469-2477.

Iglesias-Puig, E. and Haros, M. 2013. Evaluation of performance of dough and bread incorporating chia (Salvia hispanica L.). European Food Research and Technology, 237(6): 865-874. https://doi.org/10.1007/s00217-013-2067-x

ISTA. 2012. International rules for seed testing, edition 2012. Did you mean: International Seed Testing Association Bassersdorf, Switzerland.

Jame, Y.W. and Cutforth, H.W. 2004. Simulating the effects of temperature and seeding depth on germination and emergence of spring wheat. Agricultural and Forest Meteorology, 124(3-4): 207-218. https://doi.org/10.1016/j.agrformet.2004.01.012

Khajeh-Hosseini, M., Powell, A.A. and Bingham, I.J. 2003. The interaction between salinity stress and seed vigor during germination of soybean seeds. Seed Science and Technology, 31(3): 715725. [In Persian with English Summary]. https://doi.org/10.15258/sst.2003.31.3.20

Kibinza, S., Vinel, D., Côme, D., Bailly, C. and Corbineau, F. 2006. Sunflower seed deterioration as related to moisture content during ageing, energy metabolism and active oxygen species scavenging. Physiologia Plantarum, 128(3): 496-506. https://doi.org/10.1111/j.13993054.2006.00771.x

Kucera, M. and Turner, R. 1973. Changes in activity of proteases during embryogenesis of Anagasta kuehniella (insecta). Comparative Biochemistry and Physiology Part B: Comparative Biochemistry, 44(2): 577-585. https://doi.org/10.1016/0305-0491(73)90031-X

Leal, C.C.P., Torres, S.B., de Lima Dantas, N.B., Aquino, G.S.M. and Alves, T.R.C. 2020. Water stress on germination and vigor of 'Mofumbo'(Combretum leprosum Mart.) seeds at different temperatures. Revista Ciência Agronômica, 51(1): 1-7. https://doi.org/10.5935/1806$\underline{6690.20200013}$ 
Maguire, J.D. 1962. Speed of germination aid in selection and evaluation for seedling emergence $\begin{array}{lllll}\text { and vigour. } & \text { Crop } & \text { Science, } & \text { 176-177. }\end{array}$ https://doi.org/10.2135/cropsci1962.0011183X000200020033x

Matthews, S. and Khajeh Hosseini, M. 2006. Mean germination time as an indicator of emergence performance in soil of seed lots of maize (Zea mays L.). Seed Science and Technology, 34: 339347. https://doi.org/10.15258/sst.2006.34.2.09

Mohssen Nasab, F., Sharafi Zadeh, M. and Siadat, A. $\neg 2010$. Study the effect of aging acceleration test on germination and seedling growth of wheat cultivars in controlled conditions (in Vitro). Crop Physiology Journal, 2(7): 59-71. [In Persian with English Summary].

Panahi, M., Akbari, G.A. Roustakhiz, J. and Golbashi, M. 2012. Response of safflower genotypes (Carthamus tinctorius L.) to salinity stress via germination and early seedling growth. Iranian Journal of Seed Science and Technology, 1(2): 211-222. [In Persian with English Summary].

Parmoon, G., Moosavi, S.A., Akbari, H. and Ebadi, A. 2015. Quantifying cardinal temperatures and thermal time required for germination of Silybum marianum seed. The Crop Journal, 3(2): 145-151. https://doi.org/10.1016/j.cj.2014.11.003

Parmoon, G., Moosavi, S.A., and Siadat, S.A. 2019. Performance of Iranian okra ecotypes under various accelerated aging conditions. Horticultural Plant Journal, 5(1): 17-23. https://doi.org/10.1016/j.hpj.2018.09.001

Poori, K., Akbari, F. and Ghaderi-Far, F. 2012. Response of deteriorated cotton seed to salinity stress at germination and seedling growth stages. Journal of Plant Production, 19(2): 53-68. [In Persian with English Summary].

Rehman, S., Harris, P.J.C. and Bourne, W.F. 1999. Effect of artificial ageing on the germination, ion leakage and salinity tolerance of Acacia tortilis and A. coriacea seeds. Seed Science and Technology, 27(1): 141-149.

SAS Institute. 2012. SAS/OR 9.3 User's Guide: Mathematical Programming Examples. SAS Institute.

Scheer, J.F. 2011. The Magic of Chia: Revival of an Ancient Wonder Food. North Atlantic Books. $13-21$

Scott, S.J., Jones, R.A. and Williams, W.A. 1984. Review of data analysis methods for seed germination. Crop Science, 1192-1198. https://doi.org/10.2135/cropsci1984.0011183X002400060043x

Setayesh Mehr, Z. and Esmaeilzadeh Bahabadi, S. 2013. Effect of salt stress on some physiological and biochemical characteristics in Coriandrum sativum L. Journal of Plant Production, 20(3): 111-128. [In Persian with English Summary].

Seyedi, A., Parsa Motlagh, B. and Yazdani-Biouki, R. 2019. Introduction of Chia (Salvia hispanica L.) as a valuable crop plant and medicinal plant. Iranian Medicinal Plants Technology, 2(1): 6372. [In Persian with English Summary].

Soltani, A. 2007. Application of SAS in statistical analysis. Jehad-e-Daneshgahi Mashhad Press (2th ed.). 182p. (In Persian).

Tahmasbi, B., Ghaderi-Far, F., Sadeghipour, H.R. and Galeshi, S. 2015. Enhanced accumulation of fatty acids and lipid hydroperoxides during ageing of sunflower seeds. Journal of Plant Process and Function (Iranian Society of Plant Physiology), 4: 73-83. [In Persian with English Summary]. 


\title{
Research Article
}

\section{Investigation of Seed Germination Responses of Aged Chia (Salvia hispanica) Seeds to Different Levels of Salinity Stresses by Three Models}

\author{
Amin Haghighi ${ }^{1}$, Yazdan Izadi ${ }^{2}$, Miad Haji Mahmoudi ${ }^{1}$, Seyed Amir Moosavi ${ }^{3, *}$
}

\section{Extended Abstract}

Introduction: Seed germination and seedling emergence depend on the genetics of plant species and are also influenced by environmental factors. Genetics and nutritional status of the maternal plant, maturity stage at a time of harvest, and environmental factors such as temperature, salinity, drought, and soil fertility influence seed germination. Seed vigor as the main parameter of seed quality decreases due to accelerated aging and storage. The objective of this study was to evaluate the response of accelerated aged Chia seed to different levels of salinity stress.

Material and Methods: Two-way factorial experiment with experimental factors including five levels of seed accelerated aging durations $(0,24,48,72,96 \mathrm{~h})$ and six levels of salinity stress $(0,50,100,150,200$, and $250 \mathrm{mM}$ ) was arranged based on a complete randomized block design with three replications. The experiment was conducted at seed technology laboratory of Khuzestan Agricultural Sciences and Natural Resources University of Khuzestan, in 2019.

Results: Results of analysis of variance revealed that the effect of seed accelerating aging, salinity stress, and interaction effects of both factors on all measured germination traits were significant $(\mathrm{p}<0.01)$. The best pattern of seed germination was evaluated using three-parameter sigmoid models (logistic, Gompertz, and sigmoidal) and two polynomial models (quadratic and cubic), then the performance of all models was compared using $\left(\mathrm{R}_{\text {adj }}^{2}\right.$ ), root square of the mean (RMSE) and corrected Akaike index (AICc). Results showed that at accelerated aging duration, models' performance to describe Chia seed germination response varied at different levels of salinity stress. At no aging and $72 \mathrm{~h}$ of accelerated aging treatments, the sigmoidal model exhibited the best fit on final seed germination, whereas for the other levels of accelerated aging, Gompertz exhibited the best fit. Based on the output of the sigmoidal model, for no aging and 72 hours of accelerated aging, $50 \%$ of seed germination was declined at 171.7 and $76.9 \mathrm{mM}$, respectively, and based on the results of the Gompertz model, after 24 and $48 \mathrm{~h}$ of accelerated aging, seed germination declined to $50 \%$ at 163.8 and $129.6 \mathrm{mM}$. Results obtained from fitting polynomial models on seed germination showed that the cubic model provides reasonable descriptions for studied traits such as seed vigor.

Conclusion: Chia seed germination was sensitive to salinity and accelerated aging treatments. At no aging condition, Chia seeds tolerate salinity stress up to $200 \mathrm{mM}$ and were able to germinate. By increasing aging durations, seed germination declined dramatically at all salinity levels and after 96 hours of aging, there was no seed germination at $150 \mathrm{mM}$.

Keywords: Accelerated aging, Nonlinear regression models, Osmotic stress, Seed vigor.

\section{Highlights:}

1- The best nonlinear model to study accelerated Chia seed response to salinity stress was selected using the model selection criterion.

2- Chia seed germination threshold to salinity stress was determined for not- aged and aged seeds.

\footnotetext{
Former Master student of Seed Science and Technology Department of Plant Production and Genetics, Agricultural Sciences and Natural Resources University of Khuzestan, Khuzestan, Iran

2 Ph.D. Candidate Department of Plant Production and Genetics, Faculty of Agriculture, Shahid Chamran University of Ahvaz, Ahvaz, Iran

3 Assistant Professor, Department of Plant Production and Genetics, Agricultural Sciences and Natural Resources University of Khuzestan, Khuzestan, Iran
}

* Corresponding author, E-mail: amirmoosavi@asnrukh.ac.ir

http://dorl.net/dor/20.1001.1.23831251.1399.7.2.11.0

DOI: $10.29252 /$ yujs.7.2.171

(Received: 09.03.2020; Accepted: 12.08.2020) 